\title{
SEISMIC TOMOGRAPHY AND ITS IMPLICATION STRUCTURES USING REGIONAL SEISMIC PHASE RECORDED IN SYRIAN NATIONAL SEISMIC NETWORK AND SURROUNDING NETWORKS
}

\author{
Randa Mohamad', Mohammad Al-Samara², and Eric \\ Sandvol ${ }^{3}$ \\ ${ }^{I}$ Syrian National Earthquake Center, Damascus, SYRIA, PhD student \\ ${ }^{2}$ Higher Institute of Earthquake studies and research, University of \\ Damascus, Damascus, SYRIA, Supervisor. \\ ${ }^{3}$ Department of Geological Sciences, University of Missouri Columbia, \\ Missouri USA, Supervisor
}

(Received October 12, 2011 Accepted November 12, 2011)

Tomography or production of earth image using seismic waves similar to CAT scan stands for medicine computerized axial tomography using ultrasound, gama rays, or X-rays to produce a focused image of the structures across a specific depth within the body by sending signals through an object in different directions and add the signals to construct a cross section of the object.

In this study we focused on Lg attenuation in Syria using the waveforms data recorded at 57 stations for 340 events in Syria and surrounding areas to determine values of $\mathrm{Lg} Q 0$ ( $Q$ at $1 \mathrm{~Hz}$ and its frequency dependence) by using the standard two-station method. These values are used to derive a tomographic model of laterally varying $Q 0$ for Syria and surrounding areas. The Lg QO calculated values varies between 60 and 400. The lowest $Q$ values are located in northwestern Syria beneath the triple junction of the Arabian, African, and Eurasian plates. We also observe high Lg attenuation along the northern segments of the Dead Sea fault system, Aleppo plateau, southwestern of Palmyra fold-and-thrust belt, and in eastern region of Syria beneath Rawda and Qamichli Uplifts. We found moderately high $Q$ values along the North-South trending zone that cross the Palmyride fold and thrust belt through central Syria. There are two distinct high $Q$ anomalies: one concentrated beneath Rutbah uplift, and the other in northwestern portion of the Palmyra fold-and-thrust belt and north Euphrates basin. We found that the Lg QO tomographic model and its power-law frequency dependence $\operatorname{Lg} \eta$ correlate well with regional tectonic trends within Syria and the surrounding regions. Furthermore, we observe that Lg attenuation is sensitive to the upper crustal structure.

As well as in this study we used the Pn Seismic phases velocity for all the enter two stations paths located in Syria and we divided the velocities into two groups of Pn velocity (6.65-7.7), (7.7-8.5) km/sec, and we determined the cross points represents the anisotropic boundaries. The alignments of those anisotropic boundaries in the uppermost part of the mantle showed well correlation with the main tectonic and main structures known in Syria as Palmyra fold-and-thrust belt and we found it limited with the higher 
group velocity boundaries while the cross points with lower boundaries distributed alignment along Dead Sea fault system. Low velocity zone found trending north west-south east crossing the central Palmyra foldand-thrust belt and dividing it into two parts the northeastern and the west southern part.

KEYWORDS: Tomography, $\operatorname{Lg} Q$

Seismic Tomography ) تقانة المست الزلزالي التموغرافي ثنائي الأبعاد (Technique باستخدام الأطوار الموجية الزلزالية الإقليمية المسجلة في الشبكة الوطنية في سورية والثبكات المجاورة ومنعكساتها البنيوية

رندة محمد1

$$
\begin{aligned}
& \text { 1- المركز الوطني للاراسات والبحوث الزلزالية- طالبة دراسات عليا. }
\end{aligned}
$$

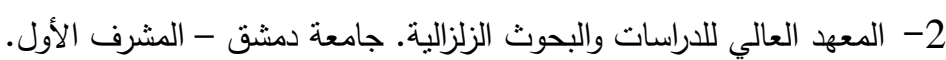

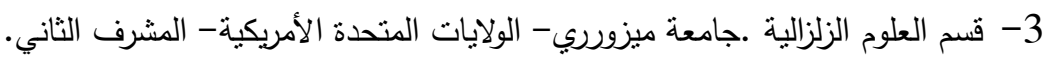

يعتبر المسح الزلزالي أو إنتاج صورة للطبقات تحت السطحية للأرض باستخدام الموجات الزلزالية مشابهاً

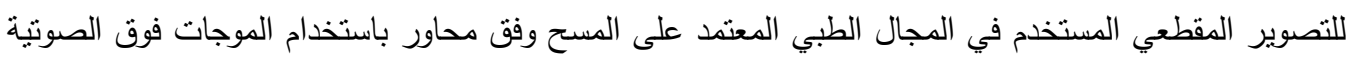

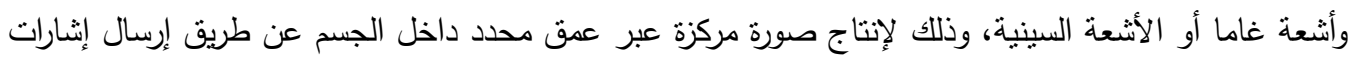

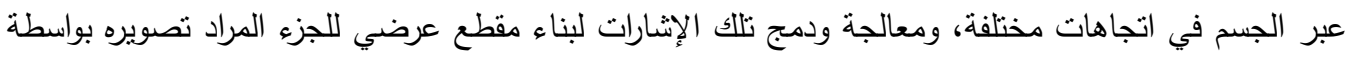

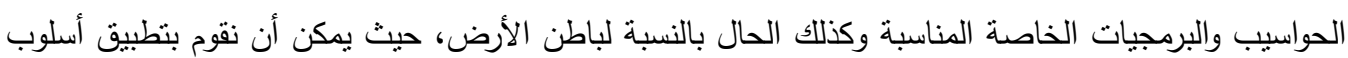
مشابه ولكن باستخدام الموجات الزلزالية.

تم في هذه الدراسة التركيز على نخامد الموجة الزلزالية Lg في سورية باستخدام البيانات الزلزالية المسجلة

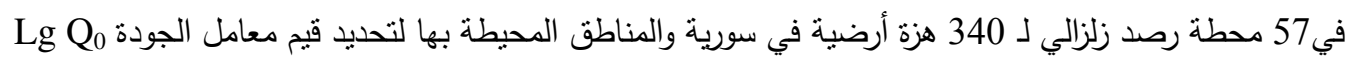
عند التردد 1 هرتز على هذه المسارات باستخدام طريقة المحطنين. استخدمت هذه القيم للحصول على النموذج

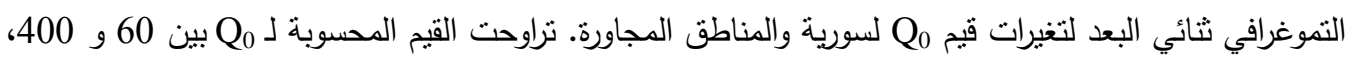
وقد تركزت القيم المنخفضة في شمال غرب سورية في المنطقة الواقعة ضمن نطاق التلاقي الثلاثي للصفيحة

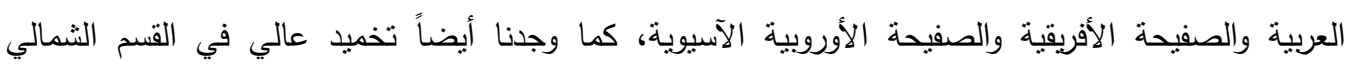
لكنظومة البحر الميت وهضبة حلب وفي جنوب غرب حزام الطي التنمري وفي المنطقة الشرقية من سورية تحت

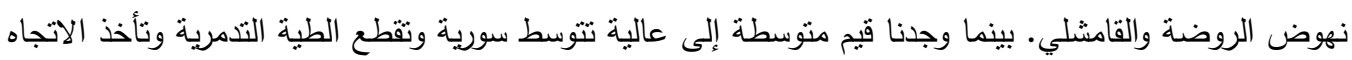

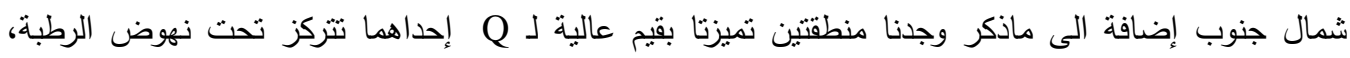

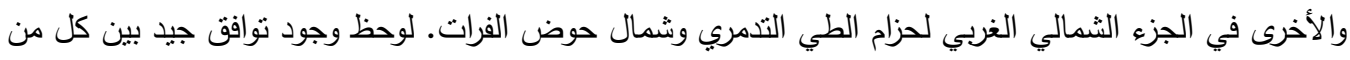


النموذجين التيموغرافيين Lg و Lو مع الاتجاهات التكنونية الإقليمية داخل سوريا والمناطق المحيطة بها، وعلاوة على ذلك لوحظ أن التوهين Lg Q0 حساس لبنية القترة الأرضية. كما تم في هذه الدراسة حساب سرعة الطور الموجي Pn لجميع المسارات بين المحطات الثنائية الواقعة في Pورية وتحديد نطاقات عدم التجانس في السرعة في السويات العليا من المعطف العلوي بتقسيم سرع الطور لتللك المسارات إلى مجموعنين (6.65-7.7) و (7.7 و 8.5) كم/ثانية. وقد أظهرت توزع نقاط عدم التجانس تلك فئل ثرابطاً جيدا مع البنيات التكتونية الرئيسية المعروفة في سورية كحزام الطي التدمري حيث وجدنا أنها محاطة بنقاط ذات مجموعة السرع الأعلى بينما كانت نقاط عدم التجانس التي توزعت على طول وبمحازاة منظومة صدوع البحر الميت ذات سرعات أقل.إضافة الى ذلك وجدنا نطاق محدد بسرعات منخفضة تجهه شمال غرب-جنوب شرق وتعبر وسط حزام الطي التدمري وتقسمه إلى جزئين القسم الثمالي الثرقي والقسم الجنوبي الغربي. الكلمات المفتاحية: التموغرافي، Lg Q، المسح الزلزالي

مقدمة :

تعتبر الزلازل من أكثر الظواهر الطبيعية حدوثًا، إذ تحدث أكثر من مليون هزة أرضية خلال العام الواحد يتم

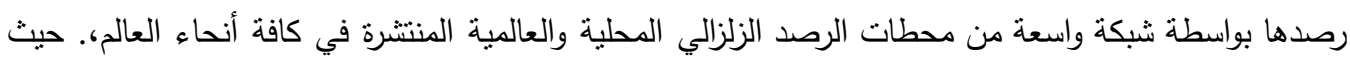
ينم من خلال معالجة تسجيلات هذه الثبكات وبالاستعانة بالبرمجيات الحاسوبية الخاصة المناسبة تحديد مواقع وأعماق النطاقات النشطة زلزالياً بدقة عالية على المستويين المحلي والاقليمي، وتعتبر الأمواج الزلزالية الناتجة عن

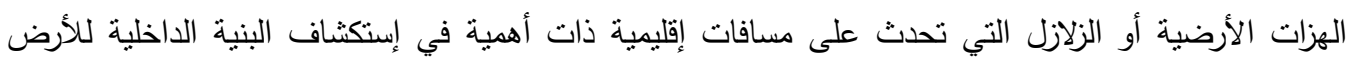
والقشرة الأرضية بالاضافة إلى أن دراسة خصائص انتشارها وسلوكها عبر المسارات التي تسلكها لها منعكسات كبيرة في تحديد الأخطار الزلزالية والتخفيف منها. لقد أستخدمت الأمواج الزلزالية المسجلة في محطات الرصد الموزعة في كافة أنحاء العالم والثبكات المحلية بنجاح خلال العقود السابقة للإستدلال على بنية الأرض وتركيبها الداخلي (الثكل 1)، وإن معظم المعلومات

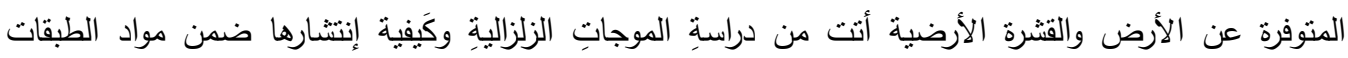
المختلفة للأرض، لهذا كانت دراسة خصائص إنتشار وسلوك الأطوار الموجية الزلزالية المختلفة التي تولدت عن الأن

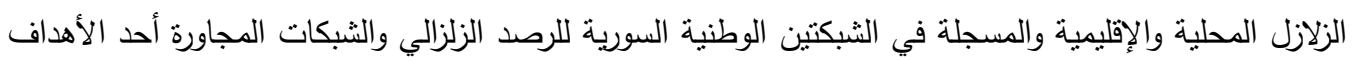
الرئيسية لهذا البحث من أجل التعرف على بنية القشرة الأرضية في سورية والبنيات التحت سطحية والمخاطر الرّل الزلزالية التي يمكن أن تتجم عن المصادر الزلزالية النشطة في سورية والمصادر الزلزالي المحيطة بها.

\section{المصادر الزلزالية الإقليمية المحيطة بسورية :}

تقع سورية بجوار الحدود النشطة للصفائح المنقاربة والمحولة وإن الوضع البنيوي والنكتوني السائد في سورية

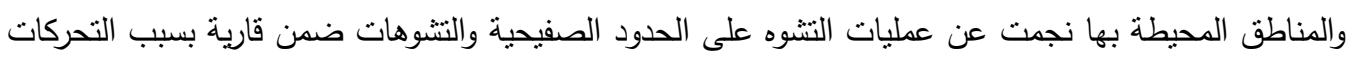
الحاصلة على هذه الحدود والتي تمنلت بالظواهر الطبوغرافية الأساسية لسلاسل الأناضول وجبال زاغروس في شمال المنطقة نتيجة التصادم بين الصفيحتين العربية والأوراسية والحدود المحولة المتمثلة بنظام صدع البحر 
الميت الحدود بين الصفيحة العربية والصفيحة الأفريقية إضافة إلى النتوهات الداخلية ضمن القارية التي حصلت

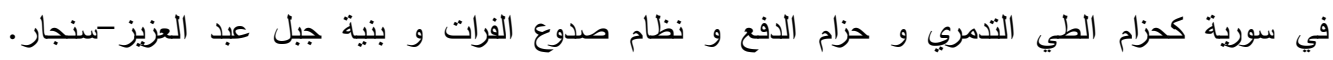
.(Graham, 2001) (McClusky, 2000).

إن النسبة العظمى من الزلازل المسلة في الثبكة الوطنية للرصد الزلزالي تقع على الحدود الفاصلة بين

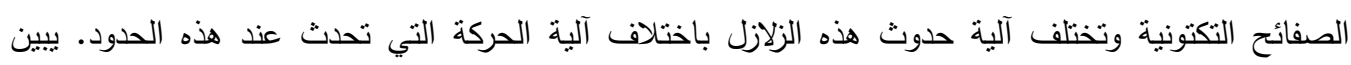

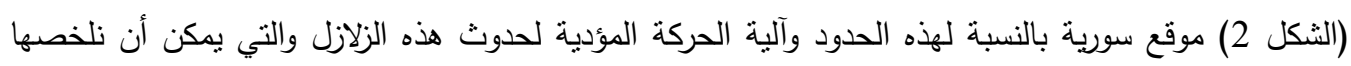

- تباعد صفيحتين عن بعضهما (النتاعد بين الصفيحتين العربية (Ar) والأفريقية (النوبية Nu) على امتداد

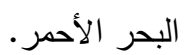

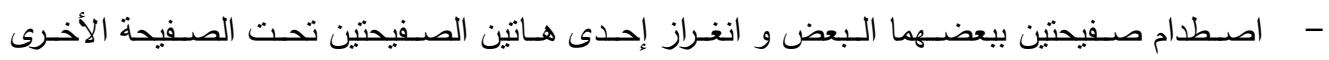

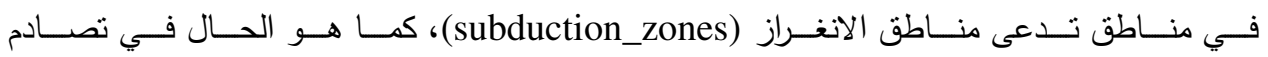

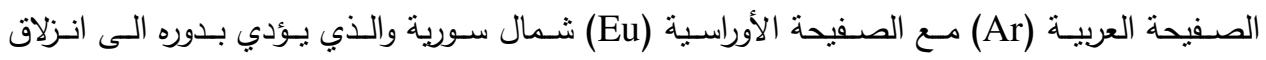

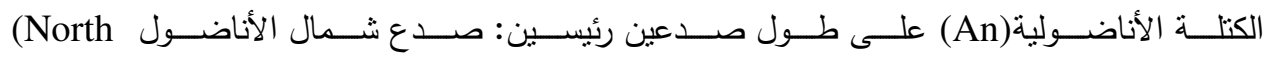

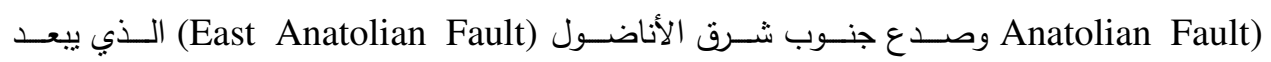
نحو 100 كم عن الحدود السورية الشمالية مع نركيا.

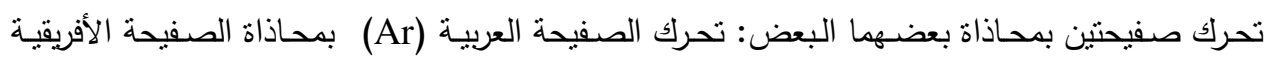

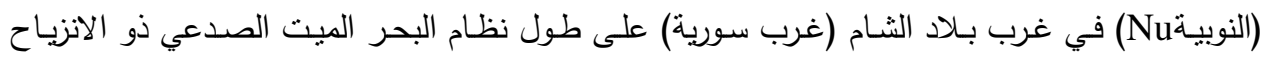

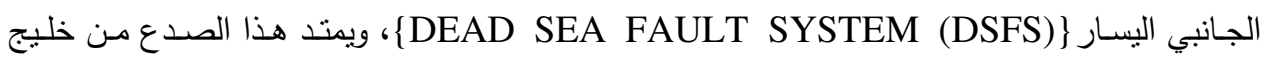
العقبة في الجنوب إلى الثمال حيث الملتقى الثناثي (Triple_Junction) للصفيحة العربية والصفيحة

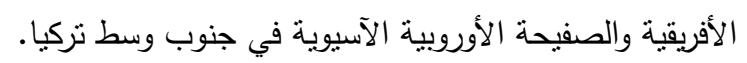

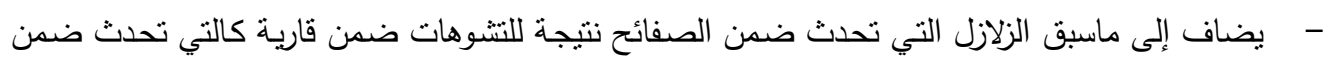

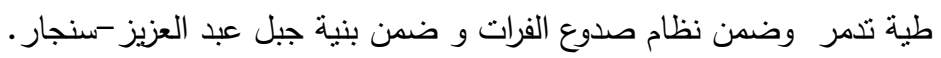

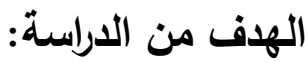

يهدف هذا البحث إلى دراسة بنية القترة الأرضية والسويات العليا للمعطف العلوي وتحديد خصائص انتشار

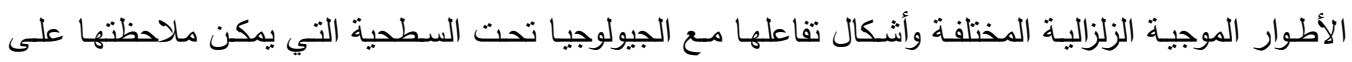

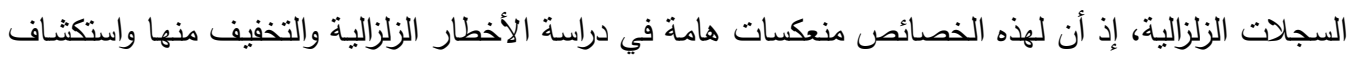

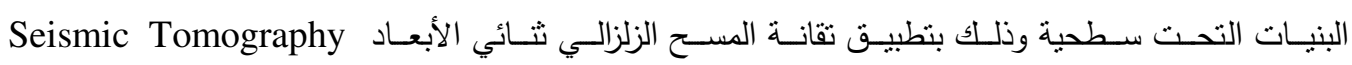
عechnique 


\section{تقانة المسح الززالي التموغرافي:Seismic Tomography Technique):}

نم في هذه الدراسة استخدام هذه التقانة بنوعيها نقانة المسح الزلزالي الأولي لوضع خرائط للتغيرات الجانبية لسرعة إنتشار الأمواج الأولية pn، وذللك لإنتاج خارطة نوزع حدود عدم التجانس في المعطف العلوي التي تعبرها تلك الأمواج ، وتقانة المسح الزلزالي الدقيق لوضع خارطة التغيرات الجانبية لتخامد الطور الموجي Lg وخارطة علاقة الطاقة المواج ولقانه المعتمدة على التردد للتعرف من خلالها على البنيات التحت سطحية ضمن القترة وتحديد النطاقات المتمايزة بخواصها وذللك باستخدام حوالي 25300 سجل زلزالي لأكثر من 340 زلزال إقليمي مسجل في 57 محطة رصد زلزالي في الثبكة الوطنية السورية والثبكات المجاورة (التركية والأردنية والقبرصية والسعودية. يبين الشكلان3 و 4 مواقع محطات الرصد الزلزالي ومواقع الزلازل الاقليمية المستخدمة في هذه الدراسة.

\section{مبدأ المسح الزلزالي المستخدم في هذه الاراسة:}

يمكن ثوضيح مبدأ هذه الطريقة بشكل عام من خلال المثال التالي: إذا افترضنا بأنه لاتوجد لدينا معلومة لتحديد موقع محافظة دمشق وريفها سوى مسارات الأقمار الصناعية التي تمر فوقها فنقوم بتمثيل المسارات المحققة للشرط بالخطوط الحمراء والمسارات الأخرى والتي لاتمر فوقها بالخطوط الزرقاء كما هو مبين في (الثنكل 5-1) فسوف نجد أن الخطوط الحمراء ستتركز في جنوب غرب سورية مشيرة إلى أن الموقع المحتمل للمحافظة هي في جنوب غرب سورية بشكل أولي ولكن ومن أجل الوصول إلى دقة أكثر في تحديد الموقع نقوم بتحديد نقاط تقاطع المسارات التي تحقق شرط المرور (ممثلة بالنقاط الحمراء) ونقاط تقاطع المسارات التي لاتحقق هذا الثرط (ممثلة بالنقاط الزرقاء) (الثكل 5-2) ثم بعد ذلك نقوم بإستبعاد نقاط تقاطع جميع المسارات الغير محققة لشرط مرورها

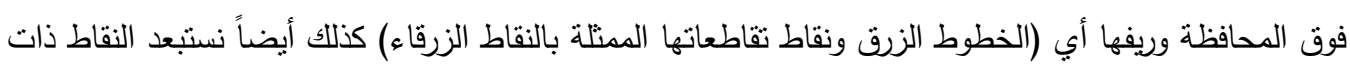
اللون الأحمر المبعثرة والواقعة خارج نطاق تجمع مثيلاتها والقريبة من النقاط الزرقاء والتي يمكن أن نعزو تواجدها إلى أخطاء صنعية في التحديد بسبب كون جميع النقاط القريبة من هذه النقاط المبعثرة زرقاء ونبقي فقط نقاط تقاطع المسارات المحققة للمعلومة ثم نقوم بتحديد حدود التجمع الرئيس للنقاط الحمر والممتلة بالبقعة الصفراء (الثكل5-3).والتي تمثل الحدود التقريبية للمحافظة وبمقارنتها مع الحدود الواقعية لهحافظة دمشق وريفها (الثكل

5-4) الممثلة باللون الوردي نجد أن التحديد جيد نوعاً ما ولكنه غير دقيق بعد.

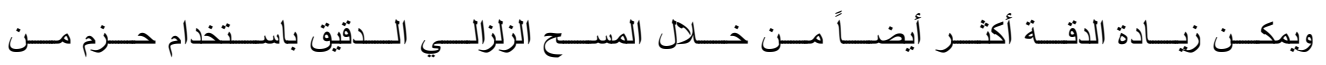

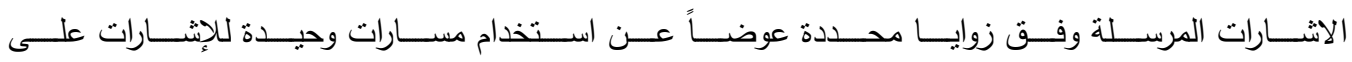

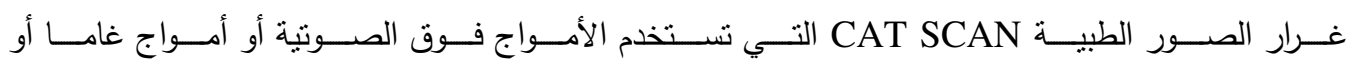

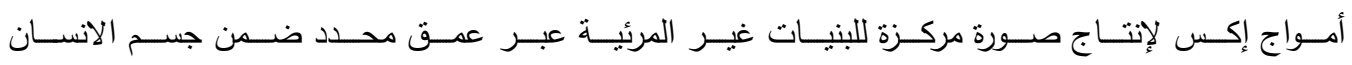

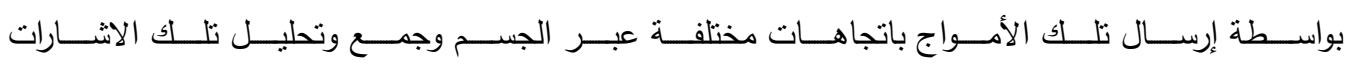

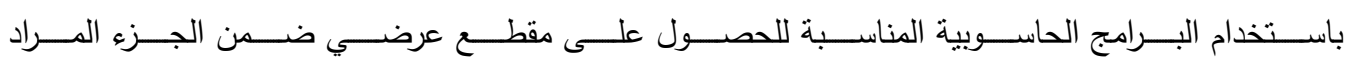

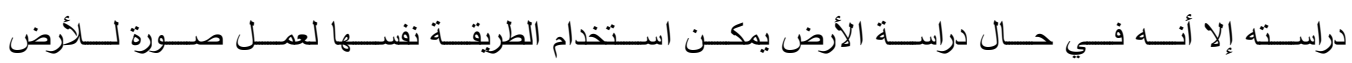

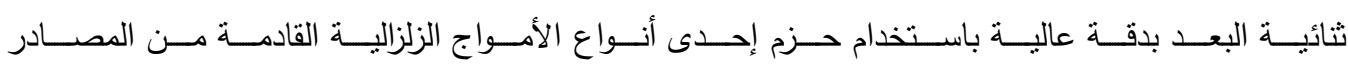




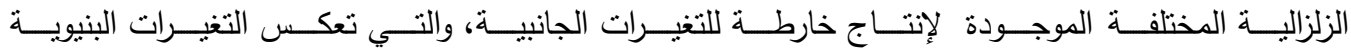

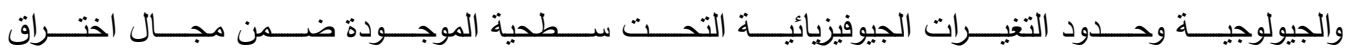

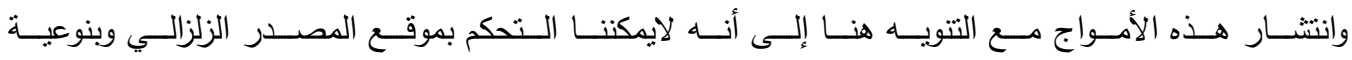

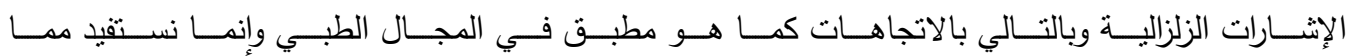
هو موجود في الطبيعة.

\section{خطوات العمل وتحضير البيانات:}

- ـ لقد نم اختيار الزلازل التي حدثت في الفترة من 1995 إلى 2008.والتي حققت الشروط التالية: أن نكون مسجلة في الثبكة الوطنية السورية للرصد الزلزالي والثبكات المجاورة لسورية الواقعة في تركيا والأردن

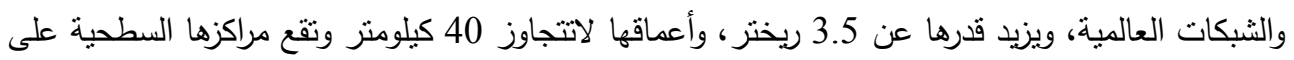

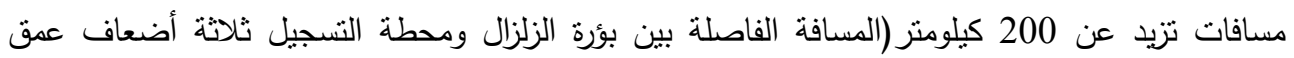

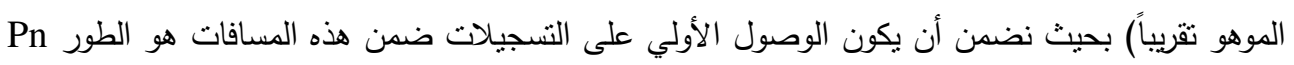
الذي ينتشر ضمن السويات العليا للمعطف العلوي. وضمان وجود الأطوار الموجية الاقليمية وخاصة الطور Lg الذي ينتشر عبر المسارات القارية في القترة الأرضية يظهر (الثكلين 3 و 4) توزع المحطات والزلازل المستخدمة في هذه الدراسة. - ازالة تأثنير استجابة أجهزة الرصد الزلزالي لكل محطة (تأثيرات السعة والطور للحساس) وقد نم التأكد من دقة هذا الاجراء باختبار عدد من المسارات للمحطات الثنائية المسجل فيهما باتجاهين متعاكسين والحصول على تئى نتائج متطابقة حيث أنه وباستخدام هذه المسارات يمكن ايجاد علاقة استجابة محطة واقعة بين المحطنين وفقاً لدراسة باو (باو وآخرون 2007) وعندما يتم ازالة استجابة المحطة بنجاح تكون علاقة الاستجابة واحدة على كامل الترددات. - - اعتماد الاحداثيات لمواقع ثوزع المراكز السطحية للزلازل التي حققت الثروط السابقة من النشرات الزلزالية الصادرة عن المساحة الجيولوجية الأمريكية USGS نظراً لدقتها حيث تقوم هذه المراكز باعادة تحديد مواقعها النهائية بدقة بتجميع كافة الوصولات الأولية للموجات الزلزالية المسجلة في شبكات الرصد الزلزالي. تحديد أزمنة الوصول الأولي والنافذة الزمنية المناسبة للطور الموجي Lg آلياً باستخدام أزمنة الوصول النظرية ضمن المجال السرعي 2.9-3.5 كيلومتز/ثانية باعنماد مواقع المراكز السطحية المحددة في الفقرة السابقة بإستخدام برنامج التحليل الزلزالي SAC إعادة تحديد أزمنة الوصول الأولي Pn بدقة على كافة السجلات الزلزالية في الثبكة السورية لهذه الزلازل على المركبة الثاقولية لحساس التسجيل بإستخدام برنامج التحليل الزلزالي SAC. ومن ثم مراجعة جميع

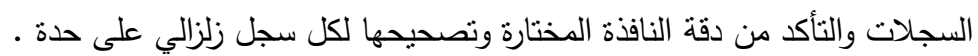
- حساب النموذج الأولي للبنية السرعية من منحني علاقة الزمن بالمسافة وإيجاد منحني الترابط الخطي لجميع

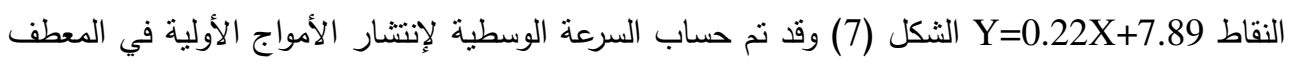
العلوي في سورية من العلاقة السابقة وبلغت 8.19 كم/ثا. 
- - اختيار جميع المحطات المسجلة للحدث الزلزالي والتي تشكل ثثائيات ثقع على استقامة واحدة مع المركز السطحي لبؤرة الهزة ان القيمة العظمى للزاوية التي على أساسها ينم إختيار الثنائيات التي على استقامة

$$
\text { واحدة مع الزلزال يساوي } 15 \text { درجة. }
$$

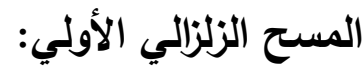

- - حساب سرعة إنتقال الأمواج الأولية Pn للمسارات بين هذه الثنائيات الواقعة في سورية، وقد نراوحت القيم المحسوبة للسرع بين 6.65 و 8.5.

- تم تصنيف المسارات وفقاً للسرع المحسوبة إلى مجموعتين المجموعة الأولى السرعات التي تتراوح بين (6.65-7.7) كم/ثا والمجموعة الثانية السرعات التي تتراوح بين (7.7- 8.5) كم/ثا. ومن ثم إيجاد نقاط التقاطع بين مسارات كل مجموعة بواسطة برنامج نظام المعلومات الجغرافي GIS، وقد بلغت عدد نقاط التقاطع بين مسارات المجموعتين 14298 نقطة تقاطع. - - تطبيق طربقة المسح الزلزالي الأولي ورسم خارطة نوزع نقاط التقاطع وفق التصنيف المعتمد سابقاً وإعطاء لونين مختلفين بواسطة برنامج نظام المعلومات الجغرافي GIS لكل مجموعة وتمثيل نقاط التقاطع للمجموعة الأولى ذات السرعات الأخفض باللون الأزرق ونقاط التقاطع للمجموعة الثانية ذات السرعات الأعلى باللون الأحمر بيين (الثكل 8) نتائج المسح الأولي.

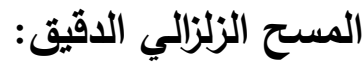

تم تطبيق طريقة المحطنين المعيارية في معاملة المعطيات لحساب معامل الجودة LgQ0 عند التردد 1 هرتز

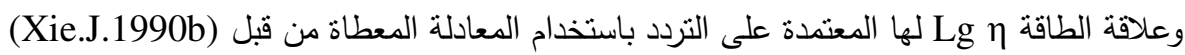

$$
\begin{aligned}
& \ln \left[\frac{v_{l g}}{\pi \Delta_{i, j}} \ln (R(f))\right]=(1-\eta) \ln f-\ln Q_{0} \\
& R(f)=\left(\sqrt{\Delta_{i}} \mid \sqrt{\Delta_{j}}\right)\left(A_{i}(f) \mid A_{j}(f)\right)
\end{aligned}
$$

3.5 Lg بالكيلومنز/ثانية.

年 $\Delta_{i}$ 
: $A_{i}(f), A_{j}(f)$

$$
\Delta_{i_{j} j}
$$

وفي هذه الطريقـة يـتم ازالـة تـأثير المصدر الزلزالـي بأخــ النسـبة لطيف الطـور المـوجي Lg للمحطتين

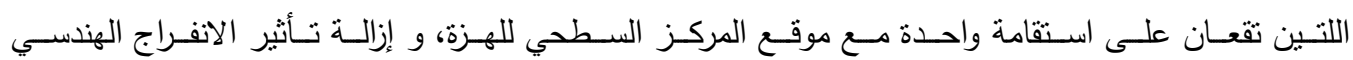

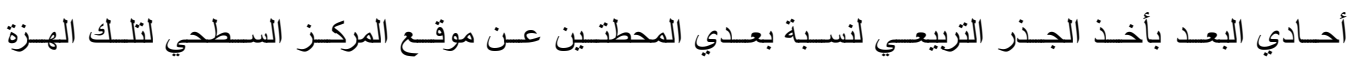

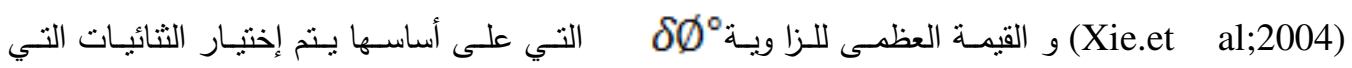

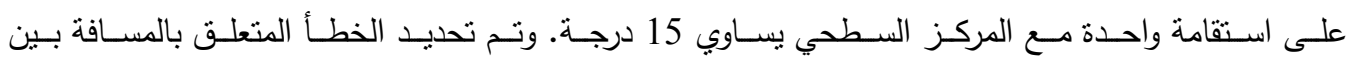
المحطتـين

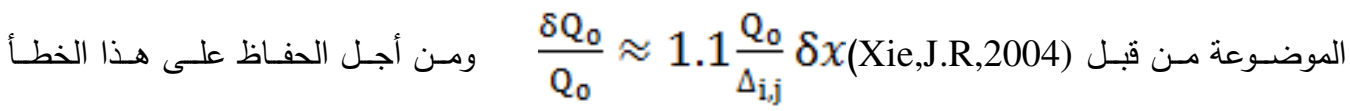

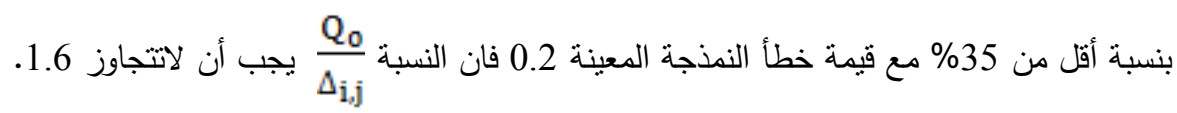

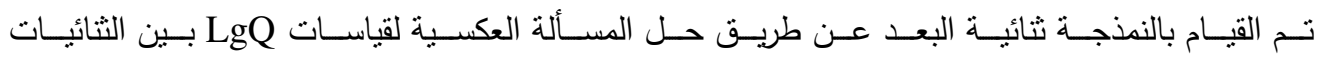
(Xie,1990)

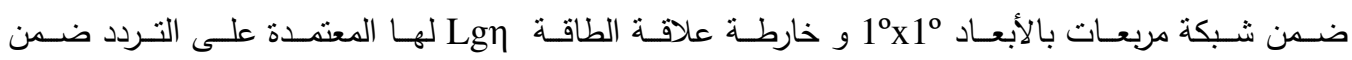
شبكة المربعات بالأبعاد

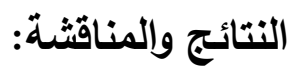 نتائج المستح الزلزالي الأولي:}

لقد تم في هذه الدراسة ولأول مرة تطبيق الفكرة الأساسية لطريقة المسح الزلزالي الأولي على سرعة إنتقال

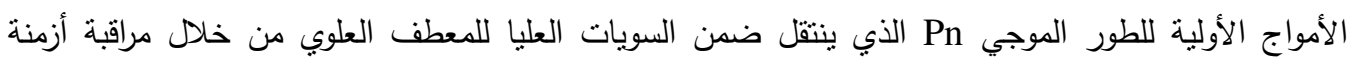

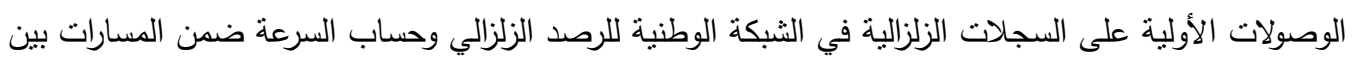

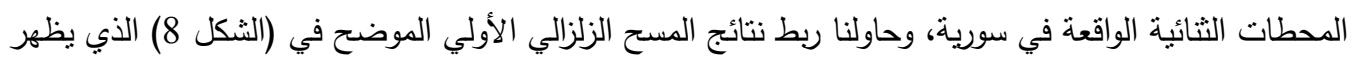
توزع نقاط عدم تجانس سرعة إنتقال الأمواج الأولية الطور Pn ضمن النمن السويات العليا للمعطف العلوي بالبنى 
الداخلية للمعطف العلوي والقشرة الأرضية في سورية وذلك بالاعتماد على حقيقة أن السرع المختلفة لانتقال الأمواج الزلزالية تعتمد على اختلاف الخصائص الفيزيائية للمواد التي تتنقل عبرها. وفيما يلي النتائج والملاحظات التي تم الحصول عليها من المسح الأولي (الشكل 8): - - تأخذ توزع نقاط عدم التجانس للمجموعتين الأولى والثانية لسرع الموجة الأولية Pn المظهر الخطي بشكل عام. - - يغلب على توزع المجموعة الأولى للنقاط ذات السرع المنخفضة للموجة الأولية Pn والممتلة في الثكل السابق باشارة الجمع باللون الأزرق الاتجاهين شمال - جنوب في غرب سورية والاتجاه شرق - غرب وأحياناً الاتجاه جنوب شرق- شمال غرب. - - يغلب على توزع المجموعة الثانية للنقاط ذات السرع العالية للموجة الأولية Pn والممنلة في الثنكل بإثارة الجمع ذات اللون الأحمر الإتجاه شمال شرق-جنوب غرب. باستثناء بعض التوزعات في شمال نهوض

$$
\text { حلب التي تأخذ الاتجاه شمال غرب-جنوب شرق. }
$$
- - نلاحظ بشكل عام تقارب خطوط حدود عدم التجانس بإتجاه الثرق للمجموعين الأولى والثانية للسرع

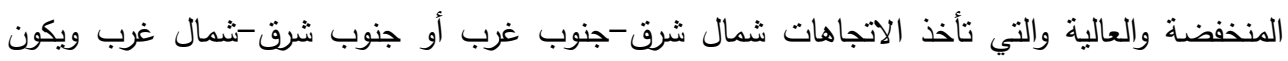
التباعد بينهم باتجاه الغرب أكبر من التباعد بينهم باتجاه الثرق. يمكن أن يعزى هذا التقارب إلى اتجاهات الحركة المسيطرة في سورية لحركة الصفيحة العربية بإتجاه الثمال مع الدوران بعكس إتجاه عقارب الساعة بهن فتؤدي هذه الحركة إلى تقارب هذه الحدود باتجاه الثرق بينما تؤدي إلى تباعدها أو إبقائها على وضعهاه باتجاه الغرب.

- لوحظ وجود نوافق بين حدود عدم التجانس لمجموعة نقاط السرع المنخفة ومجموعة نقاط السرع الأعلى

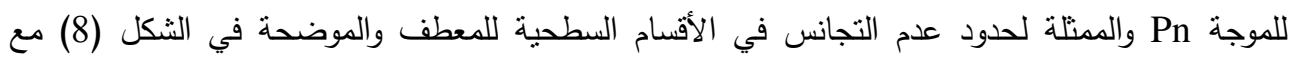
معظم المظاهر البنيوية والتكتونية الرئيسية المعروفة في سورية و تكون مسايرة لاتجاه هذه البنيات الرئيسية بشكل عام كما يلي:

أن حدود عدم التجانس الممنلة باشارات الجمع ذات اللون الأحمر لمجموعة السرع للموجة الأولية Pn الطية التذمرية الواقعة في وسط سورية وتتموضع هذه النقاط على حديها الجنوبي والثمالي بينما

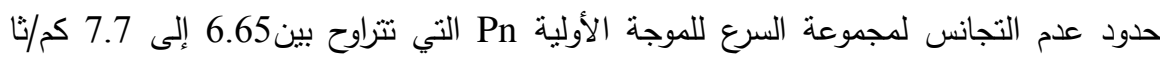

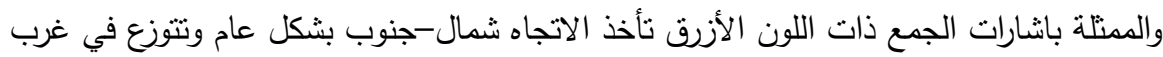
سورية بتوافق مع اتجاه صدع البحر الميت. أن حدي عدم التجانس اللذان يأخذان الاتجاه جنوب شرق هثمال غرب غرب والممثلان للمجموعة

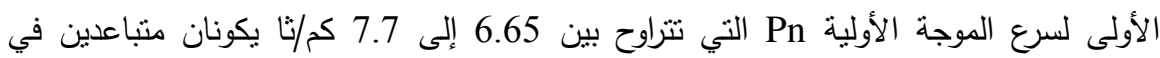
الاتجاه شمال غرب ويتلاقيان في الاتجاه جنوب شرق ويقطعان الطية التدمرية في منتصفها تقريباً ويتموضعان ضمن المنطقة المعروفة التي تفصل الطية التدمرية إلى قسميها الثمالي الثرقي والجنوبي الغربي ونسايران صدع جحار بشكل عام. قد يشكل هذا النطاق منطقة نشاط اندفاعات 
مواد ذات حرارة عالية من المعطف العلوي أو أن هذه المنطقة تتعرض إلى اجهادات كبيرة تؤدي

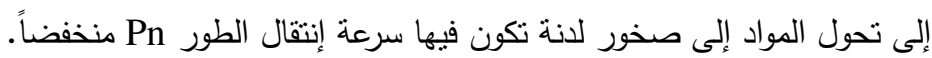

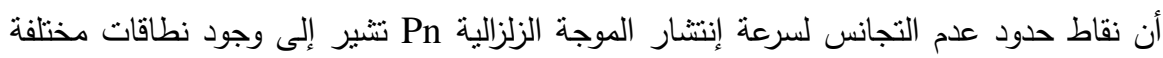

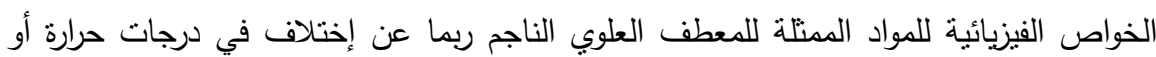
كثافة هذه المواد الشكلة للسويات العليا للمعطف العلوي والقشرة الأرضية وبالتالي فالمناطق التي

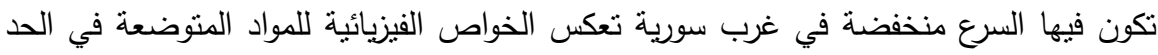

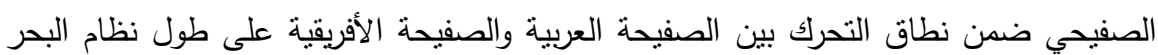
الميت الصدعي، من المحتمل أن انخفاض السرع في هذه النطاق هو بسبب وجود اندفاعات

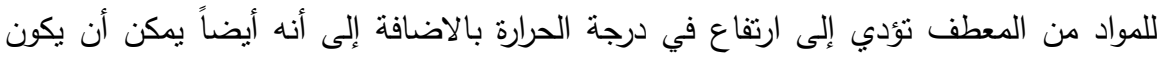
هناك تأثير للحركة الانفتاحية التي تحدث في الجزء الغربي من سورية بسبب الحركة الدورانية

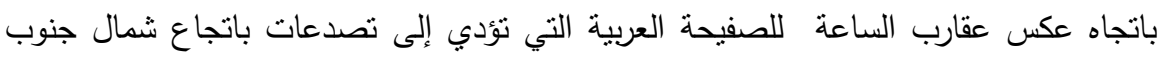
وتخلع في تلك المناطق مما يؤدي إلى انخفاض في السراب السرعة أبضاً.

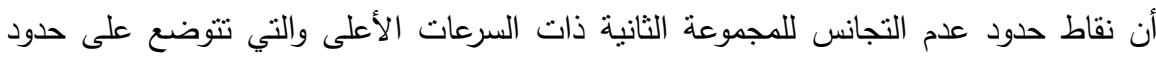

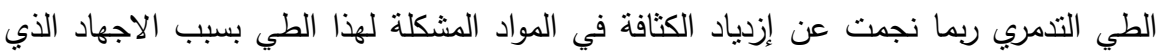
تتعرض له نتيجة كونه محور الدوران بالاضافة إلى أن المواد المندفعة من المعطف في هذاد فئه المناطق قد تكون بردت وبالتالي تكون السرعة المنوقعة أعلى.

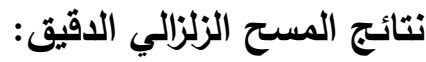

لقد تم في هذه الدراسة تطبيق السسح الزلزالي الدقيق على خاصني تخامد الطور الموجي Lg عند التردد 1هرتز

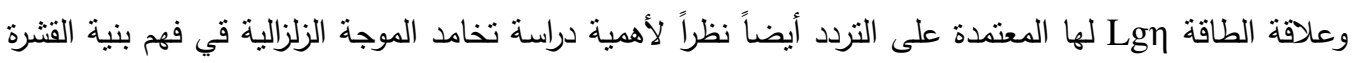

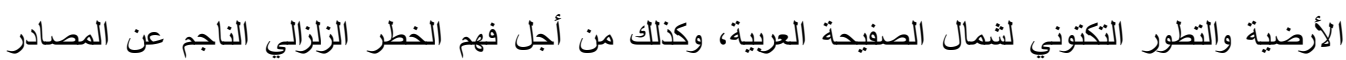

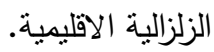

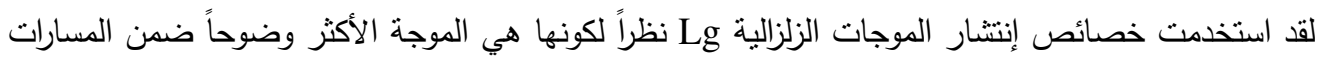

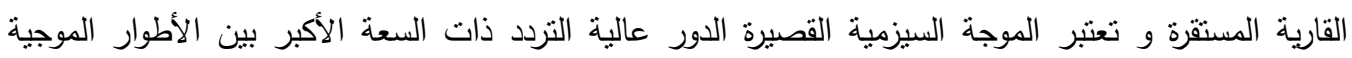

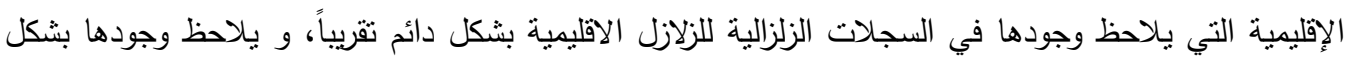
سائد على المسارات القارية وتتتقل عبر القترة القارية وتكون هي المسؤولة عن الدمار الناجم عن الزلازل الكبيرة

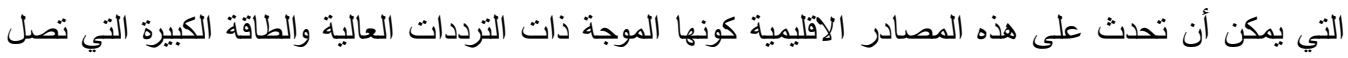

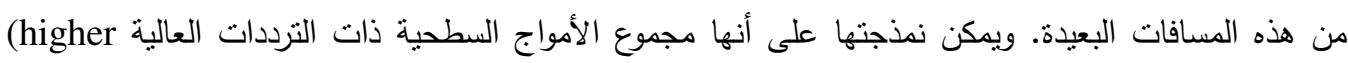

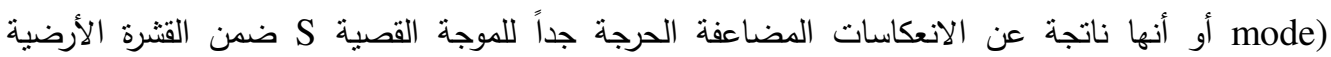
(Herrin, E, T 1960 , Buchon, M, 1983)

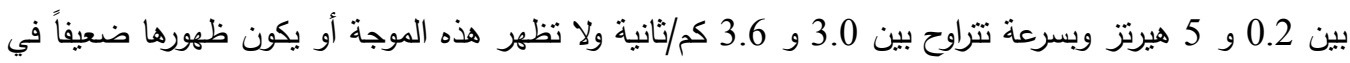
المسارات ضمن القشرة المحيطية أو القشرة القارية الرقيقة وضمن الأحواض الرسوبية العميقة وعندما تواجه 
مساراتها بتغيرات مفاجئة في سماكة القشرة الأرضية وفي المناطق اللدنة المنصهرة جزئياً في القترة الأرضية (Mitchell,1995).

لقد استخدمت خصائص إنتشار الموجات الزلزالية Lg نظراً لكونها هي الموجة الأكثر وضوحاً ضمن المسارات القارية المستقرة وهذا مايدعو إلى أهمية فهم سلوك انتشار هذا الطور الموجي في سورية.

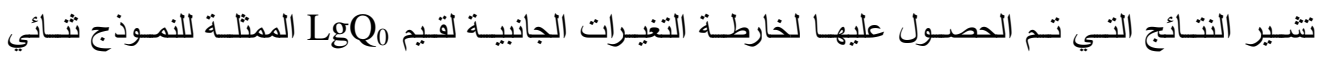
البعد المحسوب المعتمد على التردد للطور المـوجي Lg إلى تغيرات واضـحة لهذه القيم تراوحت بين 60

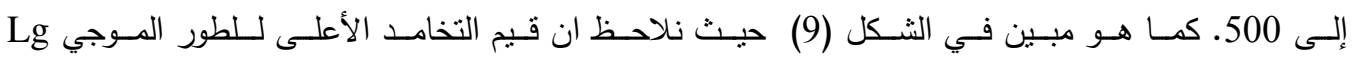

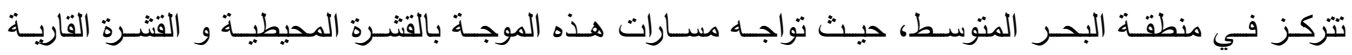

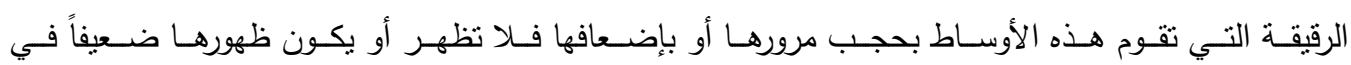

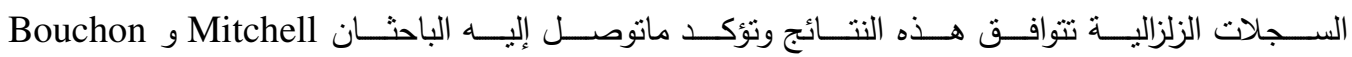
(Mitchell,1995; $\quad$ Bouchon,1982) المحيطية. وجدنا تخامد عالي لهذا الطور الموجي على طول نظام صدع البحر الميت الذي يأخذ الاتجاه شمال - جنوب و

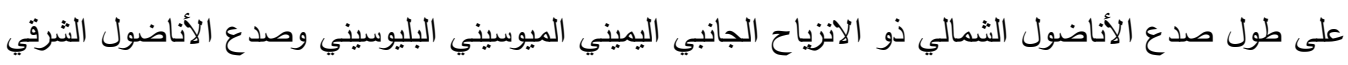
ذو الانزياح اليساري المترافق مع تحرك الصفيحة الأناضولية. يمكن أن يكون السبب لعمليات التخامد العالية التي لئي

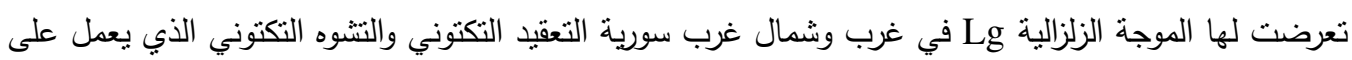

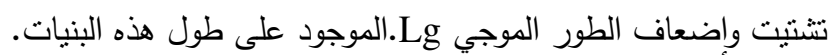
وجدت القيم التي تراوحت بين 150-225 لمعامل الجودة LgQ في الجزء الجنوبي الغربي من سورية ولبنان وتعتبر هذه القيم منخفضة نسبياً وترتبط بشكل كبير بالمنطقة الواقعة في القسم الأوسط من منظومة صدع البحر

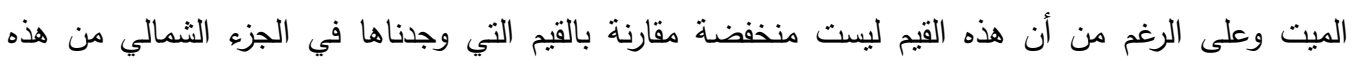
المنظومة إلا أننا لاحظنا انخفاض كبيراً في تخامد القترة على المسافة 100 كيلومتز تقريباً عن حدود الصفيحة

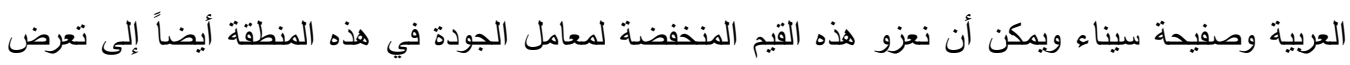

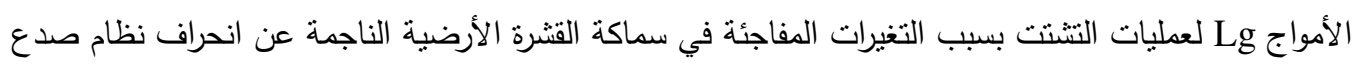
البحر الميت باتجاه شمال شرق والذي أدى إلى تغيرات كبيرة في سماكة القشرة الأرضية والذي ظهر بالتغيرات

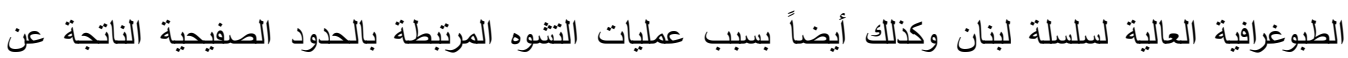
التحرك بين الصفيحة العربية وصفيحة سيناء والتي تؤدي إلى ارتفاع في درجات حرارة القثرة الأرضية وتحول بعض أجزاء في القشرة الأرضية إلى صخور لدنة ومنصهرة جزئياً تؤدي إلى إضعاف أو عدم مرور هذه الأمواج. ومن النتائج الهامة التي تمت ملاحظتها في هذه الدراسة أن معظم المسارات العمودية على إتجاه السلاسل

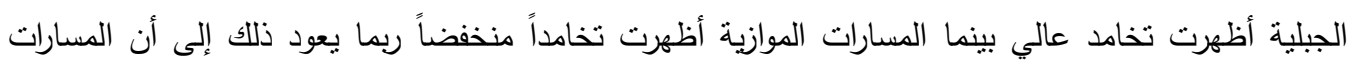
العدودية على السلاسل الجبلية تصادف بتغيرات مفاجئة في سماكة الرسوبيات على عكس المسارات الموازية لهذه الزلازل. ومن النتائج الهامة أيضاً أن التخامد الملحوظ في القسم الجنوبي الغربي من سورية شرق هذه المنطقة (حيث الانتشار الواسع للتوضعات البركانية) يمكن أن يترافق بارتفاع في درجات الحرارة في القترة وإلى إنصهار 
المواد وتحولها إلى مواد لدنة وبالتالي وسط غير مناسب لمرور الطور الموجي Lg مما يؤدي إلى انخفاض قيم ه

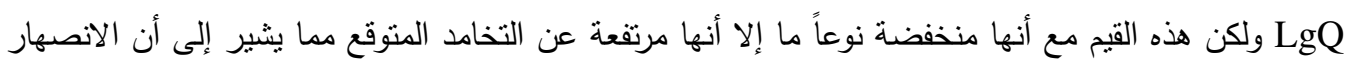

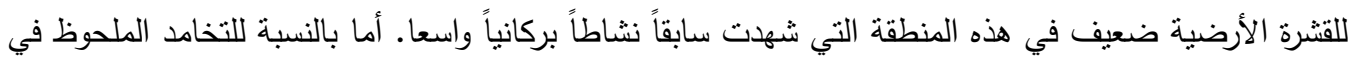

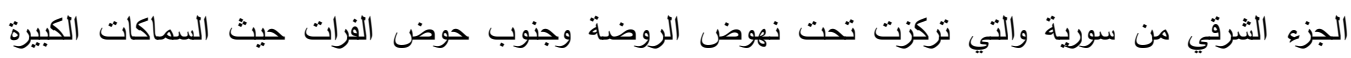

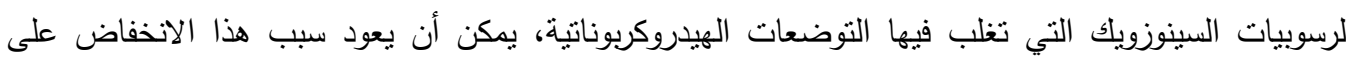

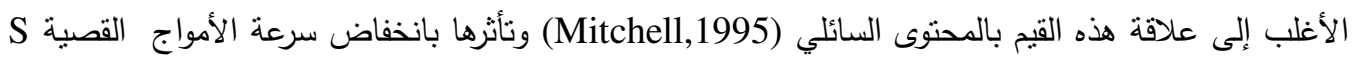
في رسوبيات هذا الحوض. وجدت القيم المتوسطة لهعامل الجودة التي تراوحت بين( 225-300) في وسط سورية أخذة الاتجاه شمال-

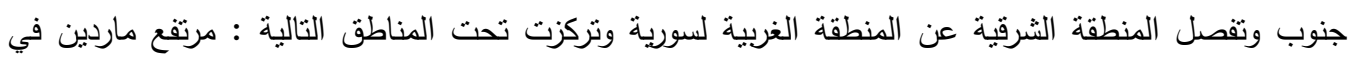

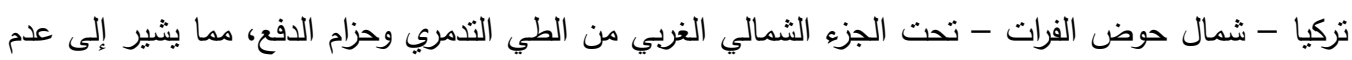

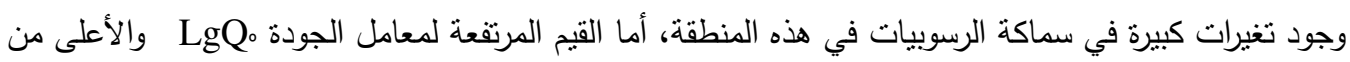
300 فقد تركزت في جنوب سورية تحت نهوض الرطبة وشرق الأردن حيث تكون فيها القشرة الأرضية مستقرة

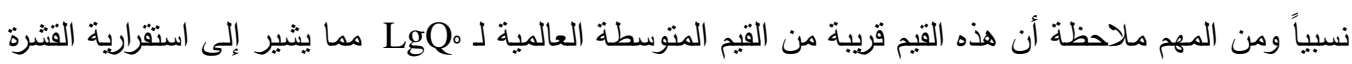
نسبياً في هذه المنطقة. أظهرت خارطة التغيرات لقيم LgQ المبينة في الثكل (9) نوافقاً جيداً مع المظاهر البنيوية والتكتونية الرئيسية

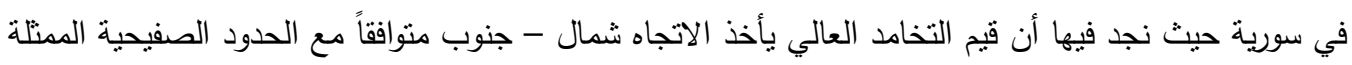

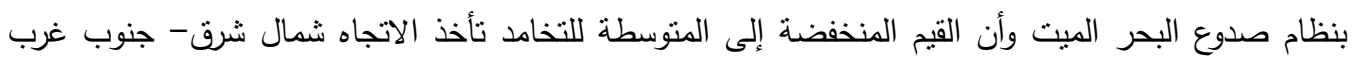

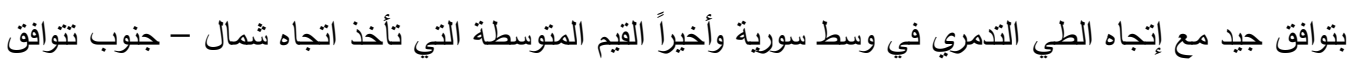

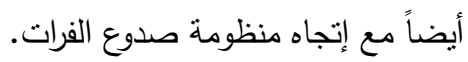

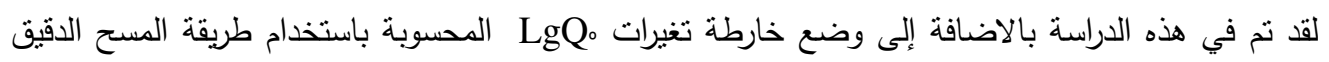

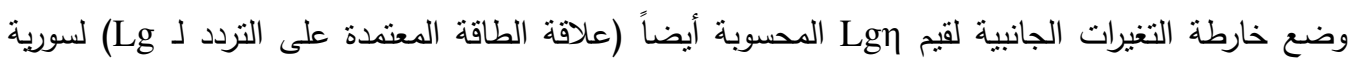

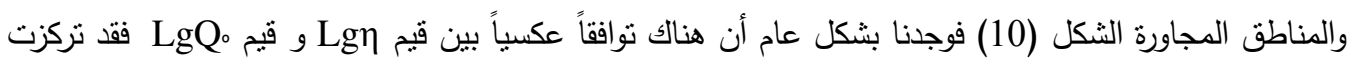

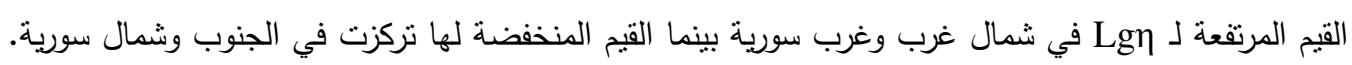

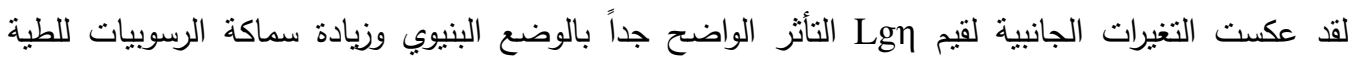

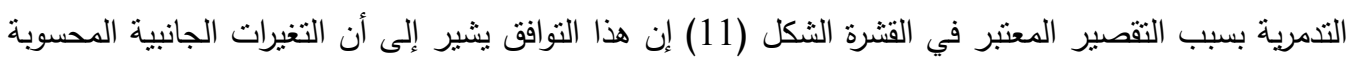

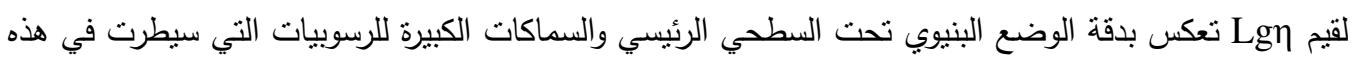
المنطقة خلال فترة الميزوزويك والسينوزويك.

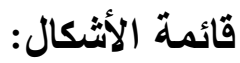

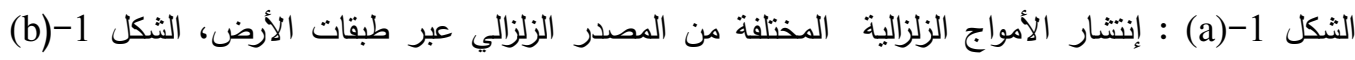

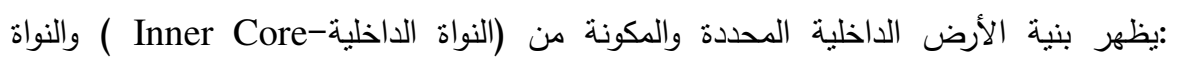


الخارجية (Outer Core) - المعطف - Mantle - وينقسم إلى المعطف السفلي -

Crust - Asthenosphere

الثكل (2): خارطة النشاط الزلزالي وآليات الحركة في بؤر الزلازل في المصادر الزلزالية المحيطة بسورية (Rilenger2006)

http://ccgm.free.fr/mediterra_geodyn_gb.html

الثكل (3): يبين مواقع محطات الرصد الزلزالي المستخدمة في هذه الدراسة. الثكل (4): يبين مواقع الزلازل الإقليمة المستخدمة في هذه الدراسة. الثكل 5: (1,2,3,4) مبدأ المسح الزلزالي وفق مسارات عشوائية.

الثكل (6): العلاقة الخطية بين زمن وصول الموجات الأولية Pn مع البعد عن المصدر الزلزالي الشكل(7): خارطة توزع نقاط عدم التجانس لسرعة إنتقال الموجة الأولية Pn في سورية. الثكل (8): خارطة التغيرات الجانبية لمعامل الجودة LgQ عند التردد 1 هرتز لسورية والمناطق المجاورة التي نم الحصول عليها في هذه الدراسة.

الثكل (a-9): خارطة التغيرات الجانبية لقيم Lgף علاقة الطاقة المعتمدة على التردد لسورية والمناطق المجاورة خارطة التغيرات الجانبية التي تم الحصول عليها في هذه الدراسة.الشكل 9-b خرائط تساوي Tectonic and Geologic سماكات الترياسي في سورية (مأخوذ من دراسة غراهام 2001) Evolution of Syria
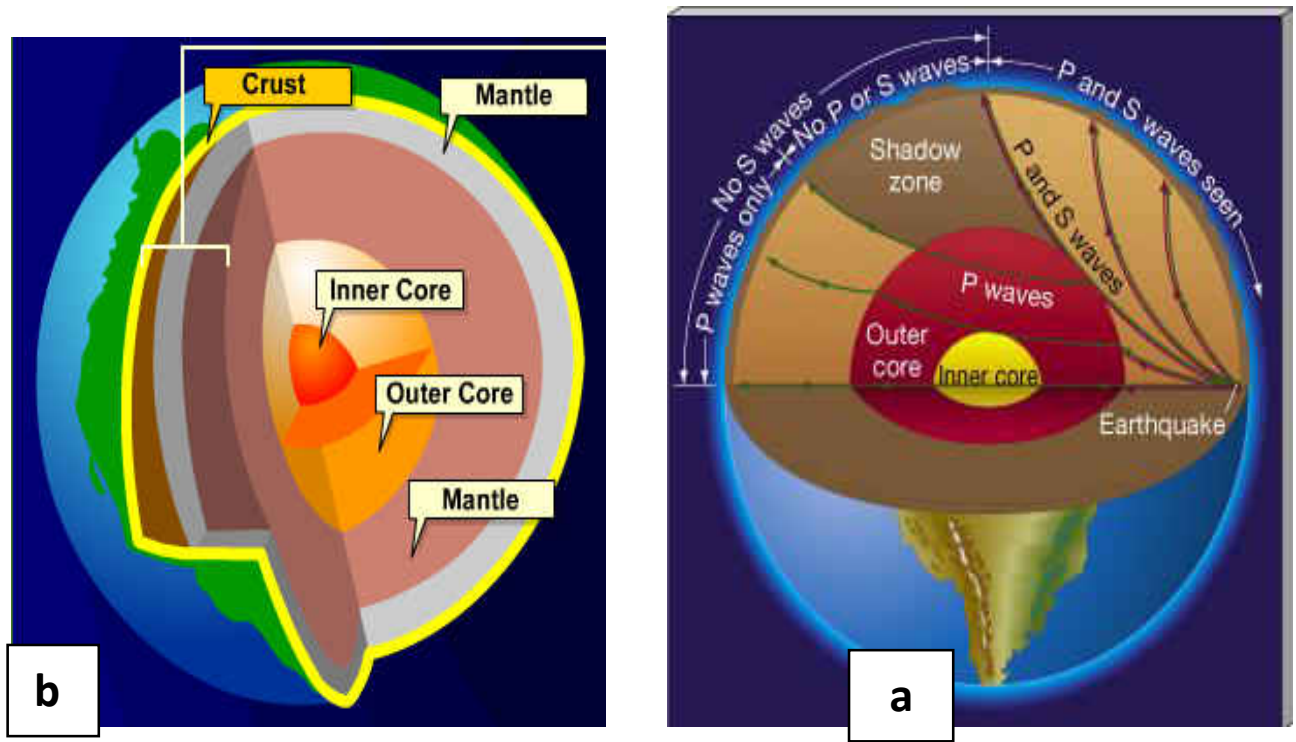

الثكل 1: (a) : إنتشار الأمواج الزلزالية المختلفة من المصدر الزلزالي عبر طبقات الأرض (b) :يظهر بنية الأرض الداخلية المحددة والمكونة من (النواة الداخلية-Inner Core ) والنواة الخارجية (Outer Core) (Lithosphere - وينقسم إلى المعطف السفلي - Asthenosphere والمعطف العطوي Crust - والقترة الأرضية 


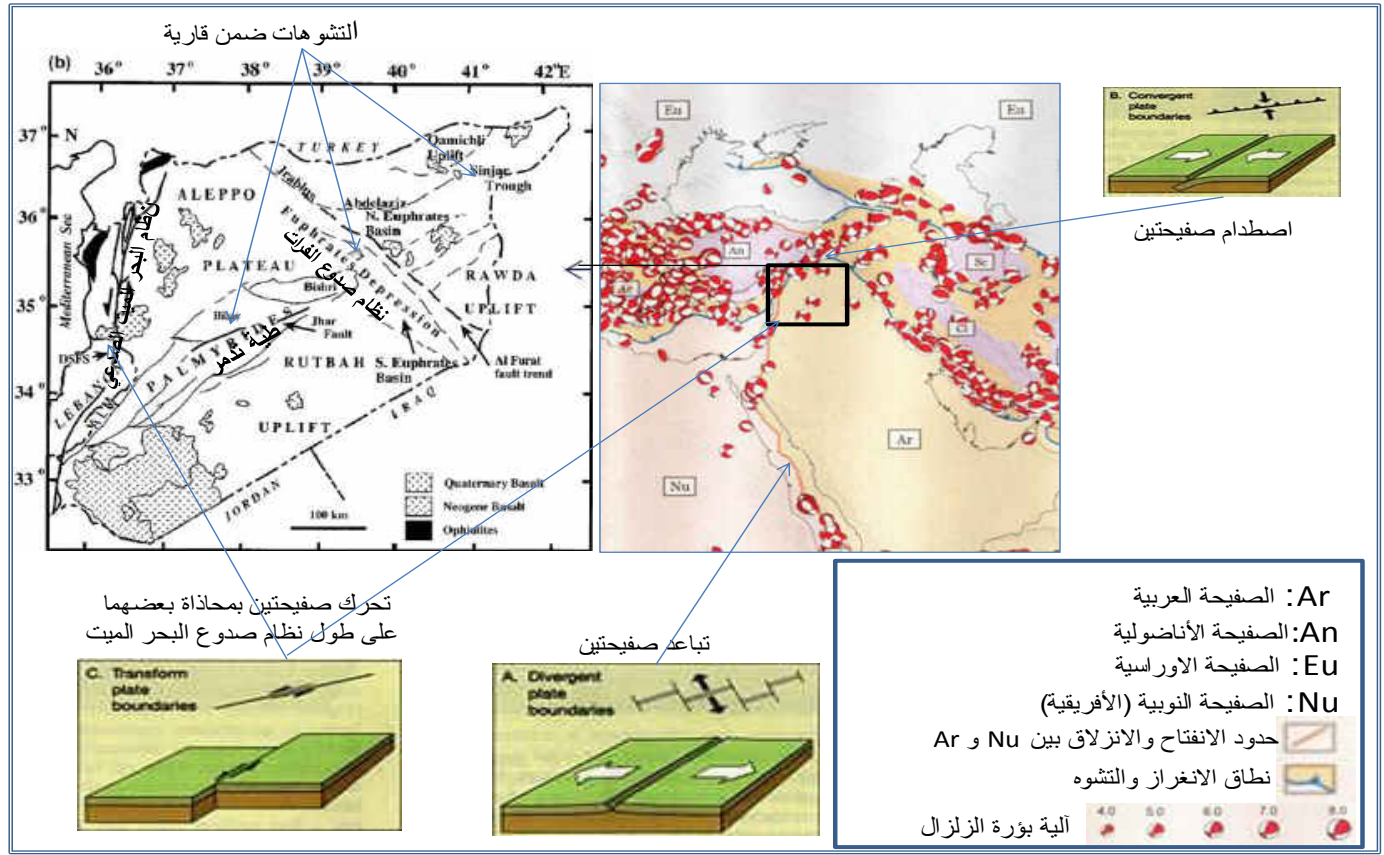

الثكل ( 2 ) خارطة النشاط الزلزالي وآليات الحركة في بؤر الزلازل في المصادر الزلزالية المحيطة بسورية

(Rilenger 2006)

http://ccgm.free.fr/mediterra_geodyn_gb.html الخارطة مأخوذة من الموقع الإلكتروني

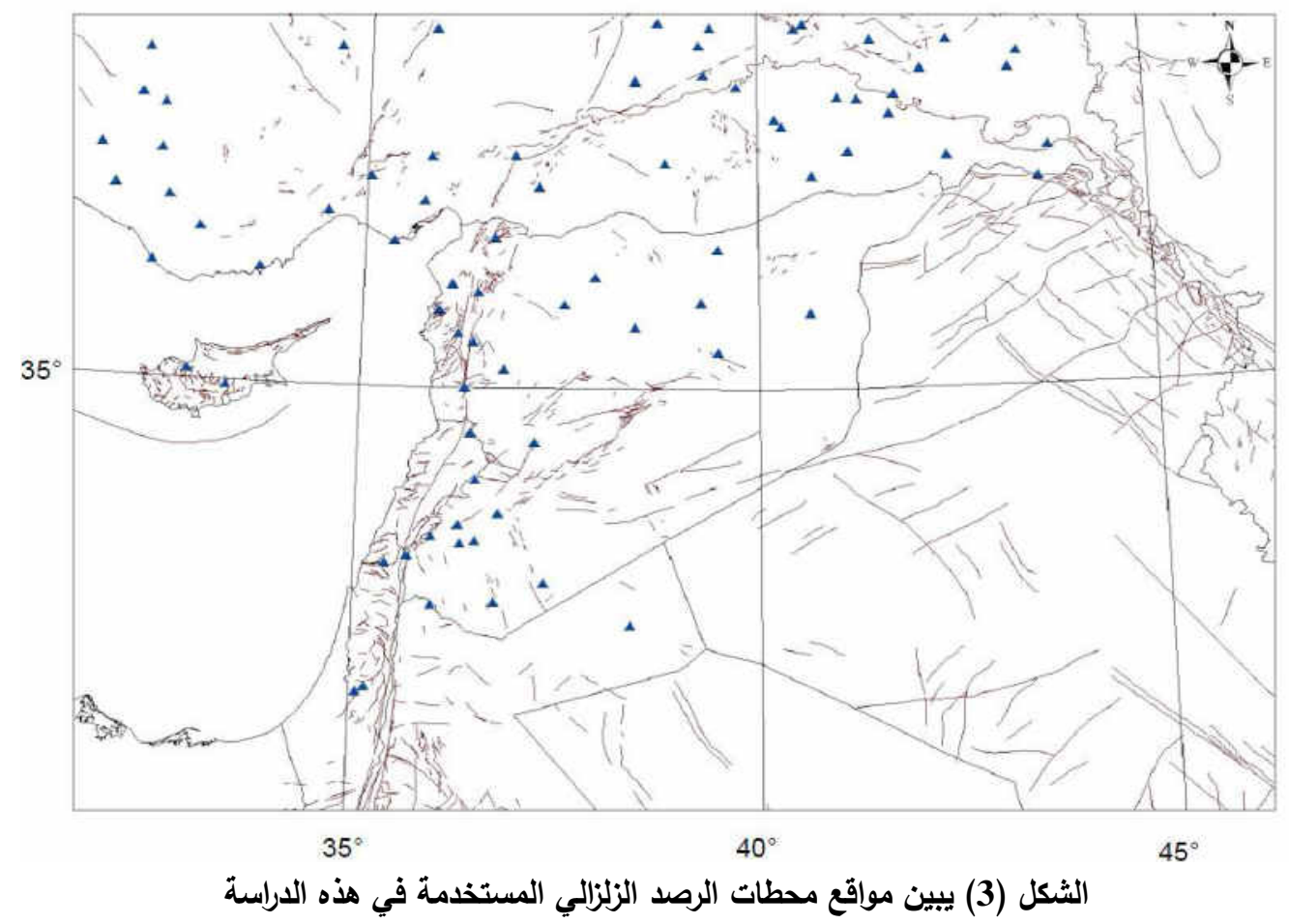




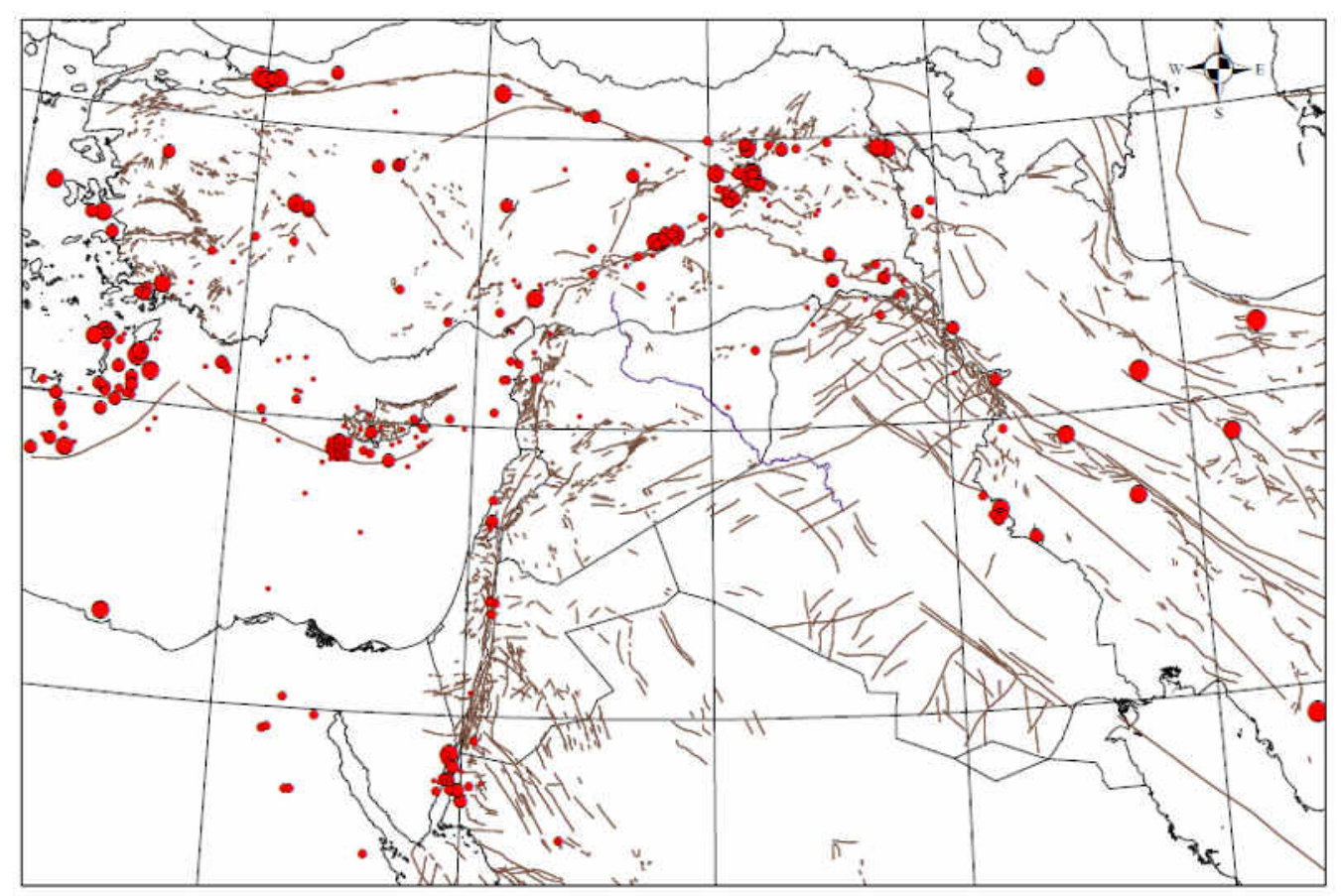

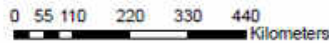

الثكل (4) يبين مواقع الزلازل الإقليمة المستخدمة في هذه الدراسة
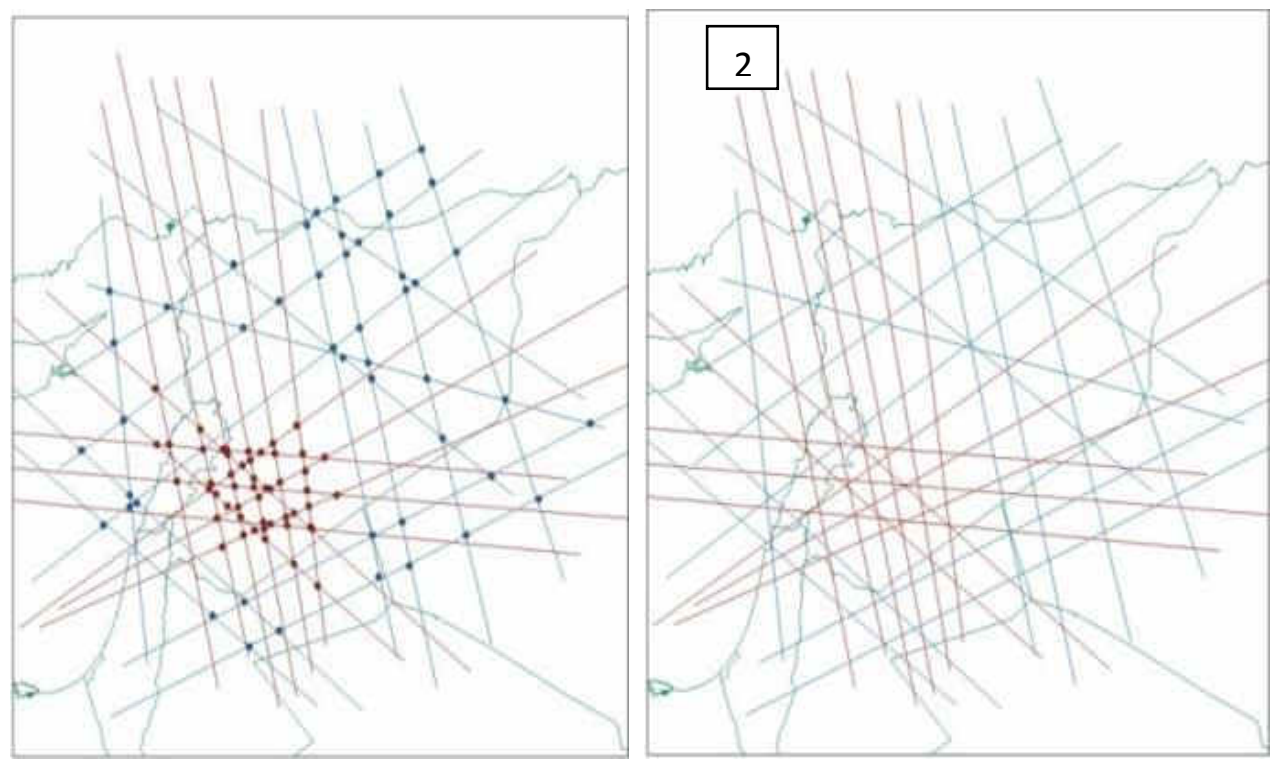


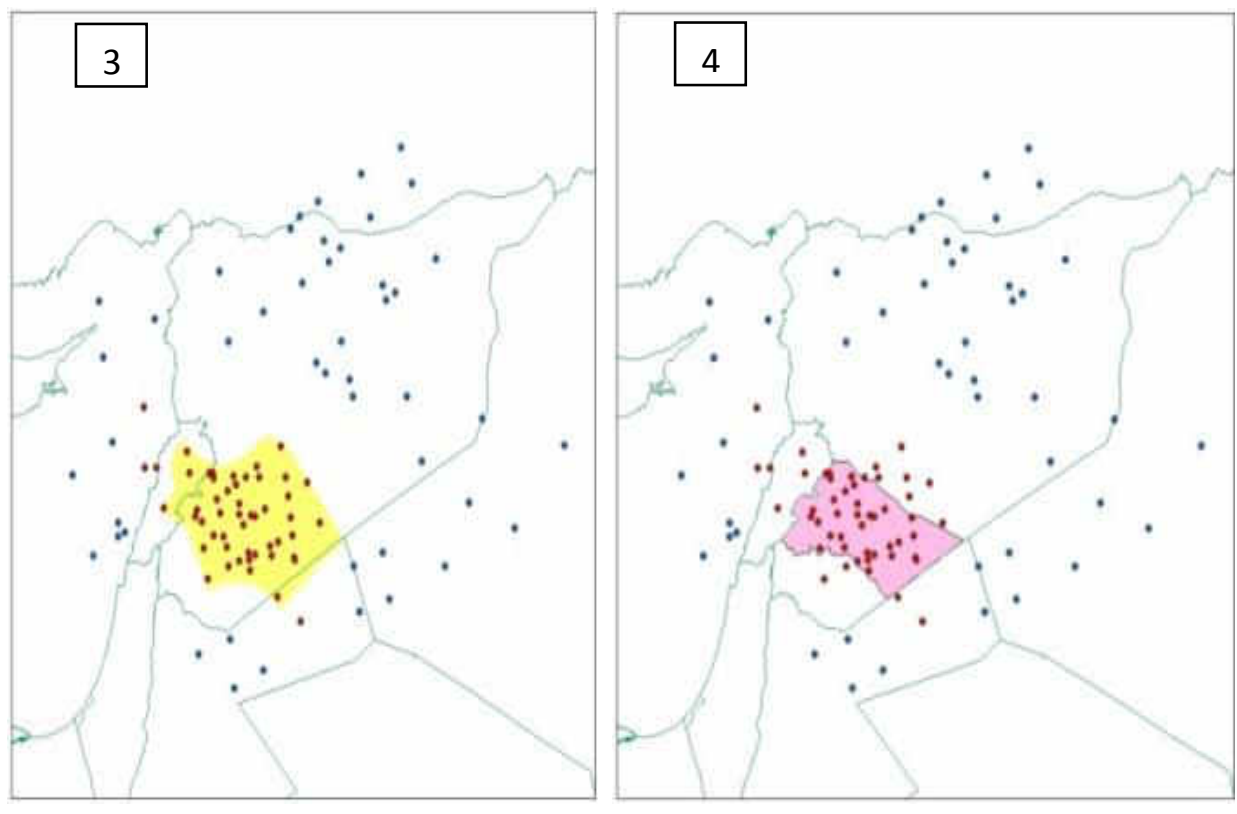

الثكل 5 (1,2,3,4) يوضح مبدأ المسح الزلز الي وفق مسار ات عشو ائية. 


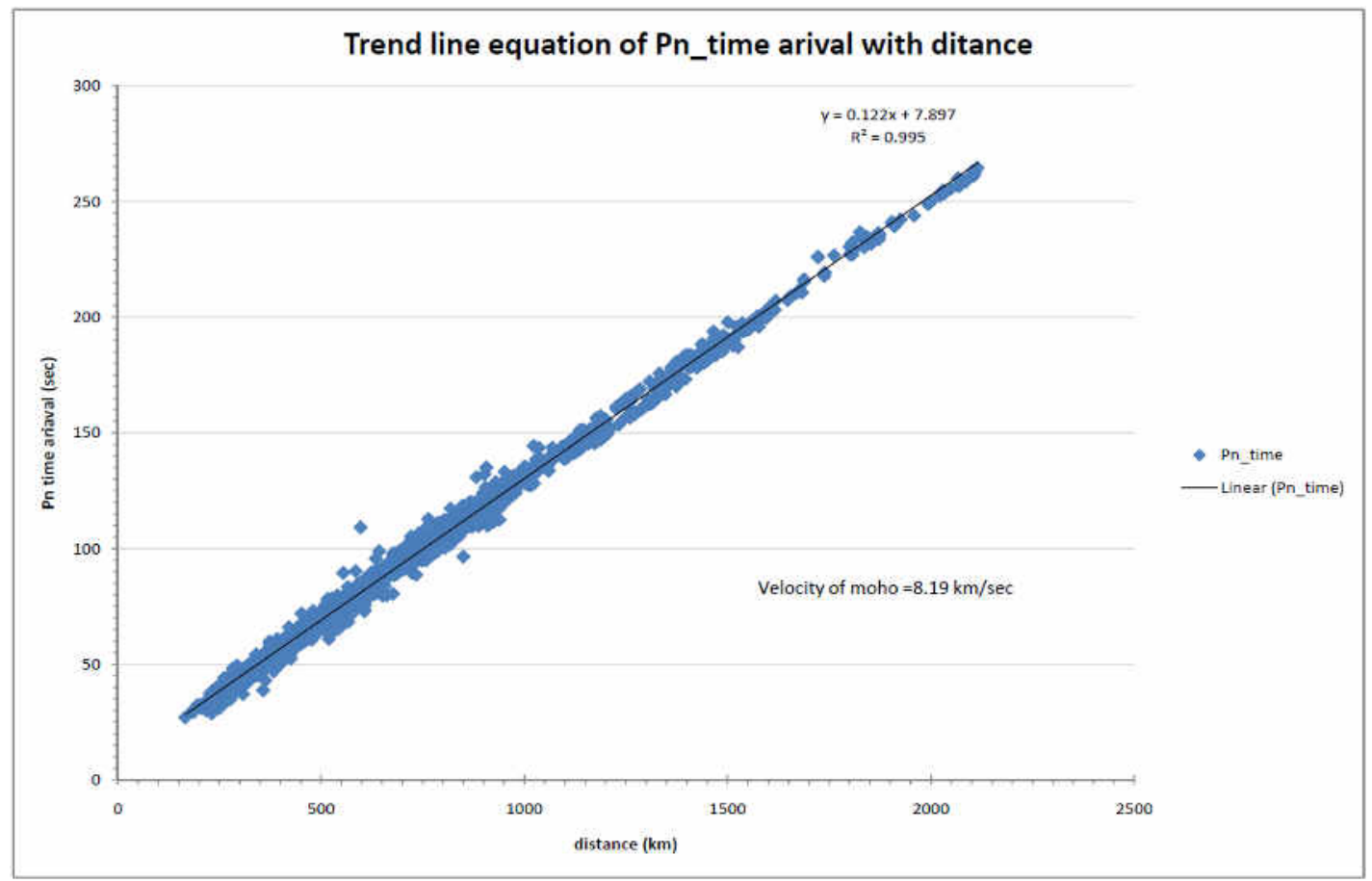

الثكل (6) العلاقة الخطية بين زمن وصول الموجات الأولية Pn مع البعد عن المصدر الزلزالي

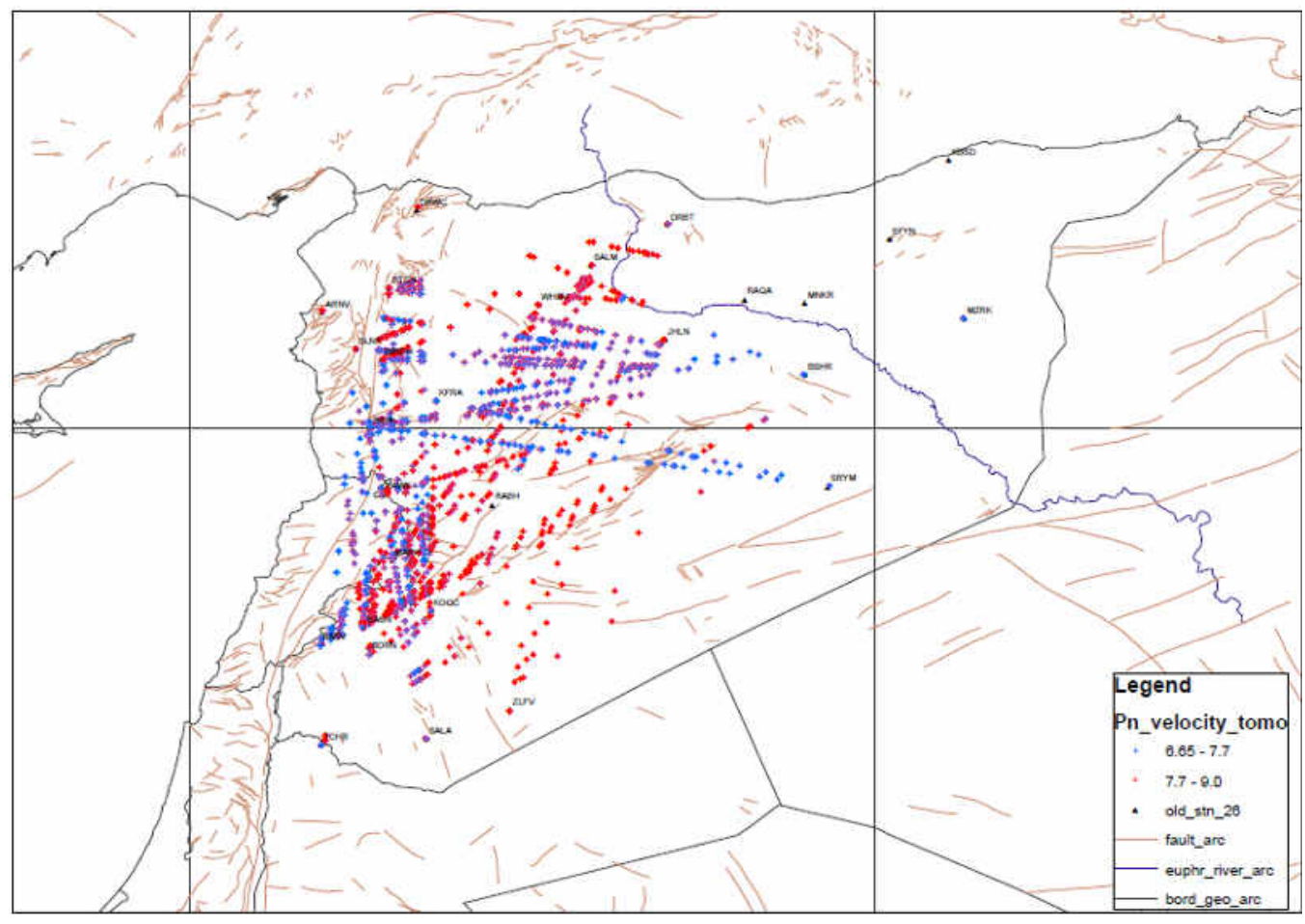

الثكل(7): خارطة توزع نقاط عدم التجانس في سرعة إنتقال الموجة الأولية Pn 


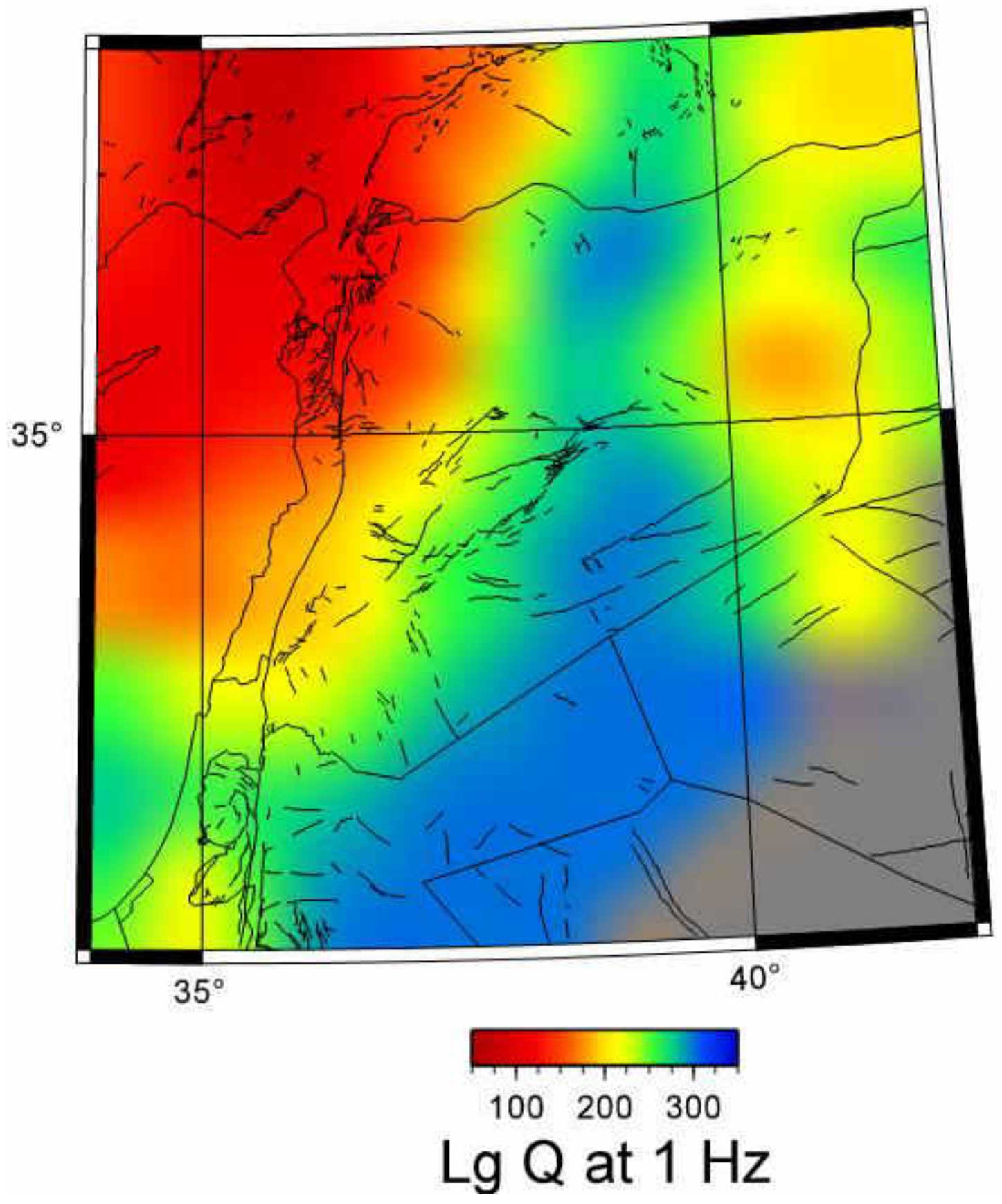

الثكل (8): خارطة التغيرات الجانبية لمعامل الجودة تم الحصول عليها في هذه الدراسة. 


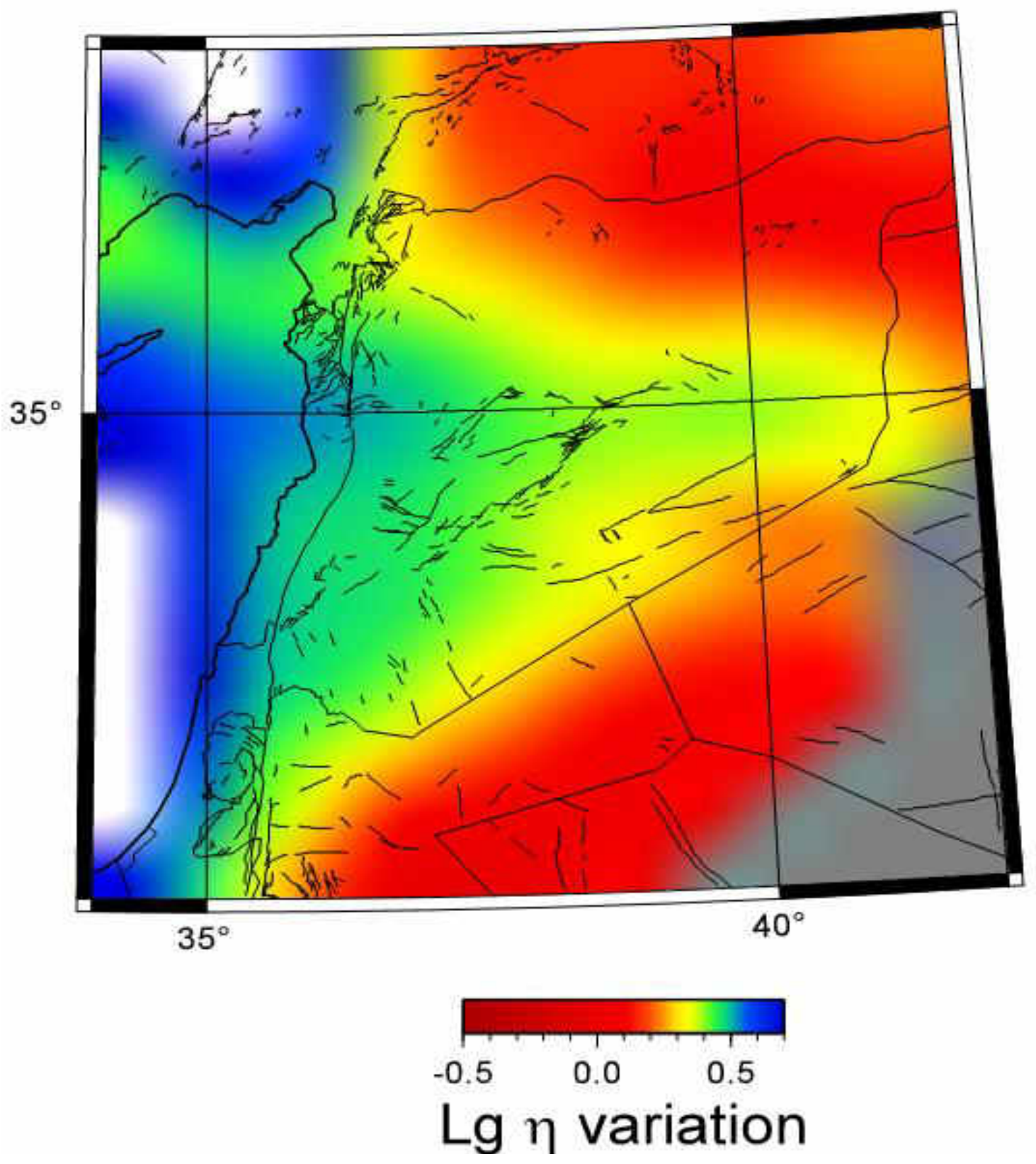

الثكل (9): خارطة التغيرات الجانبية لقيم Lg علاقة الطاقة المعتمدة على التردد لسورية والمناطق المجاورة خارطة التغيرات الجانبية التي تم الحصول عليها في هذه الدراسة. 


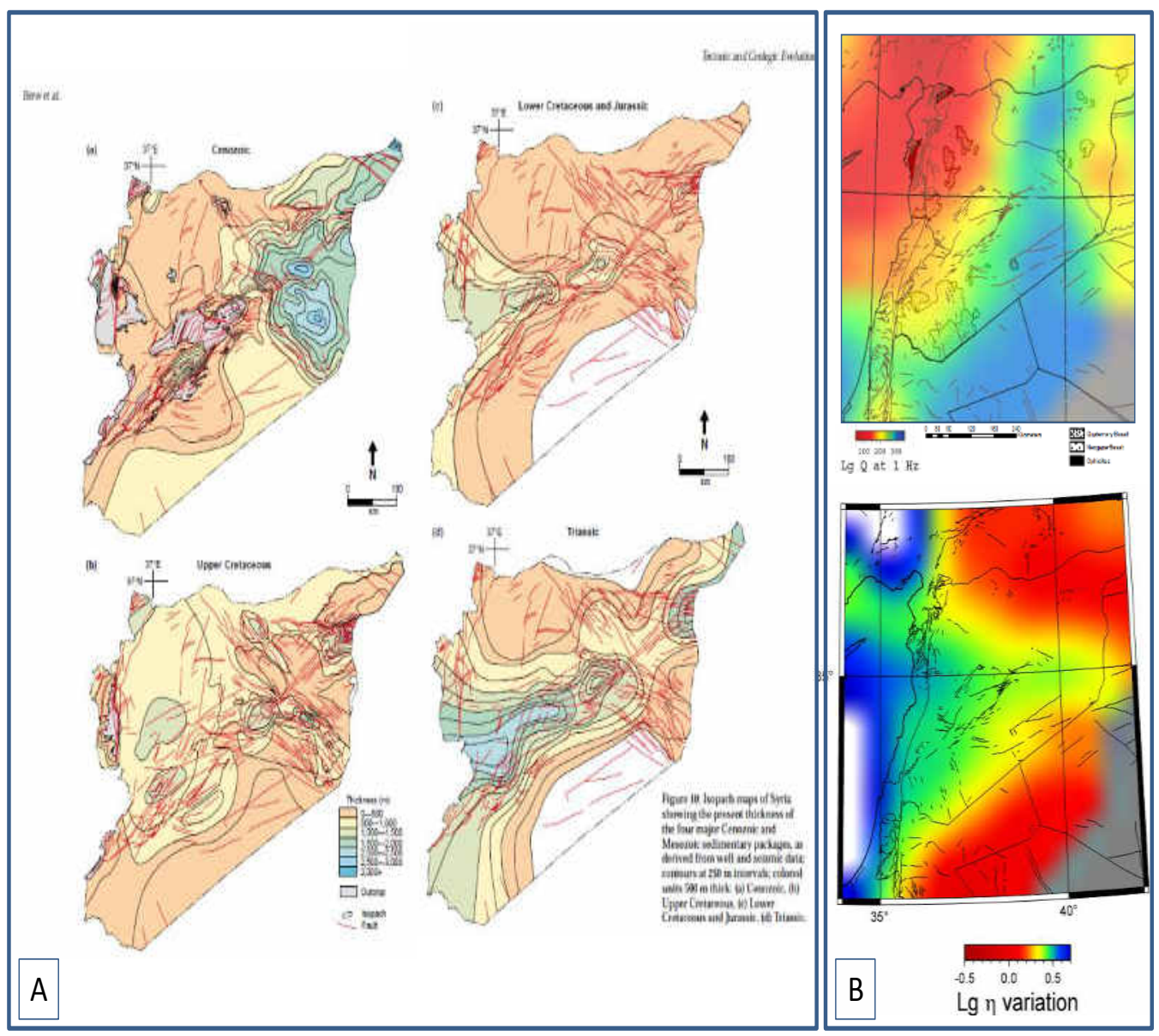

الثكل(10) مقارنة نتائج خارطة التغيرات الجانيية لمعامل الجودة (BQL (Bند التردد 1 هرتز و خارطة

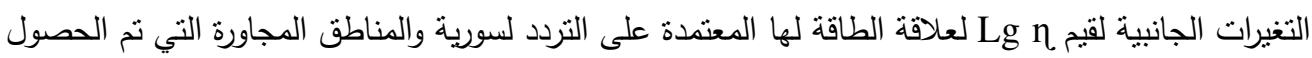

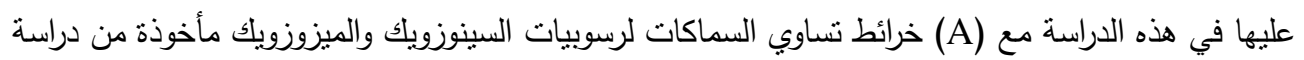
(.Graham 2001)

\section{REFERENCES}

1. Bouchon M Complete synthesis of seismic crustal phases at regional distances [Journal] // J. Geophys. Res. 87. - 1982. - pp. 1735-1741..

2. Graham B, M. Barazangi, A. Al-Maleh, and T. Sawaf, Tectonic and Geologic Evolution of Syria [Journal] // GeoArabia, Vol. 6, No. 4 . - 2001.

3. Herrin E.T., and J. Richmond On the propagation of the Lg phase [Journal] // Bull. of the Seismol. Soc. Am., 50. - 1960. - pp. 197-210.

4. J. Xie Z. Wu, R. Liu, D. Scha, Y. Liu, and J. Liang Tomographic Regionalization of Crustal $\mathrm{Lg} \mathrm{Q}$ in Eastern Eurasia GEOPHYSICAL RESEARCH LETTERS [Journal] // GEOPHYSICAL RESEARCH LETTERS, VOL. ???, XXXX, DOI:10.. - 2005. - p. Tomographic 
Regiona1029.

5. McClusky S., S. Balassanian, A. Barka, C. Demir, S. Ergintav, I. Georgiev, O. Gurkan, M. Hamburger, K. Hurst, H. Kahle, K. Kastens, G. Kekelidze, R. King, V. Kotzev, O. Lenk, S. Mahmoud, A. Mishin,M . Nadariya, A. Ouzounis, D. Paradissis, Y. Peter, M. Prilepin, R. Reilinger, I. Sanli, H. Seeger, and A.Tealeb M.N. Toksöz, and G.Veis Global Positioning System constraints on plate kinematics and dynamics in the eastern Mediterranean and Caucasus [Journal] // Journal of Geophysical Research, v. 105, no. B3. 2000. - pp. 5695_5719.

6. Mellors R., F. Vernon, V. Camp, A. Al-Amri, A. Ghalib, M. Al-Dail Regional wave propagation in the Saudi Arabian peninsula [Journal] // Geophys. Res. Lett. 104. - 1999. - pp. 20221-20235.

7. Mitchell B.J., Anelastic structure and evolution of the continental crust and upper mantle from seismic surface wave attenution, Rev. Geophys. 33, no. 4, 441-461.

8. Mitchell B.J., Y. Pan, J. Xie, and L. Cong, Lg coda Q variation across Eurasia and its relation to crustal evolution [Journal] // J. Geophys. Res. 102,. - 1997. pp. 22767-22779..

9. Xie J. and B.J. Mitchell Attenuation of multiphase surface waves in the Basin and Range province I, Lg and Lg coda [Journal] // Geophys. J. Int. 102. 1990b. - pp. 121-137.

10. Xie J. Mitchell, B.J., A back projection method for imaging large scale lateral variation in $\mathrm{Lg}$ coda $\mathrm{Q}$ with application to continental Africa [Journal] // Geophys. J. Int. 100. - 1990a. - pp. 161-181.

11. Xie J. R. Gok, J. Ni, J. and Y. Aoki Lateral variations of crustal seismic attenuation along the INDEPTH Pro_les in Tibet from Lg Q inversion [Journal] // J. Geophys. Res. - 2004. - pp. 109, B10308,doi:10.1029/2004JB002988..

12. Zor E., E. Sandvol, J. Xie, N. Türkelli, B. Mitchell, A. Gasanov, and G. Yetirmishli Crustal attenuation within the Turkish plateau and surrounding regions [Journal] // Bull. Seism. Soc. Am. 97. - 2007. - pp. 151-161.

13. Xueyang B, Eric S, Ekrem Z, Sakir S, Randa M, Rengin G, Robert M, Tea G, Gurban Y, and Niyazi T Pg Attenuation Tomography within the Northern Middle EastBulletin of the Seismological Society of America, Vol. 101, No. 4, pp. 1496_1506, August 2011, doi: 10.1785/0120100316 